\title{
Desiring Heterotopia
}

\author{
by
}

Soodeh Salehin, B.A.S.

\author{
A thesis submitted to \\ The Faculty of Graduate Studies \\ In partial fulfillment of \\ the requirements for the degree of

\section{MASTERS OF ARHITECTURE}

M.ARCH. (Professional)

\author{
School of Architecture \\ Carleton University \\ Ottawa, Ontario \\ 2006-2007 \\ (C) Copyright \\ 2007, Soodeh Salehin
}




\begin{abstract}
This thesis examines the carpet as the embodiment of mythological and cultural manifestations. Through the exploration of carpet as a craft within the early Greek and Persian societies, two different world views are investigated. For the Greeks the textile artifact was a representation of their cosmos and reflection of their logo-centric worldview .In contrast to that, for the Persians, carpets demonstrated the notion of the "garden paradise" as structuring a mythological worldview. The garden carpets are the precedent study of this thesis and act as a symbolic perfection of gardens. Ultimately the Persian carpet embodies the notion of heterotopia; therefore it is a representation of a place or a site. This thesis investigates the paradigm of the carpet as an inspirational source for all Persian art forms, postulating the question: can the Persian Carpet act as a generator of heterotopic space in the design of the International Persian Carpet Trade Centre in the contemporary context of Tehran?
\end{abstract}




\section{Table of Contents}

\section{Introduction}

\section{Part I. The Art of Persian Carpet}

1.1 Carpet as a Sacred Art of Persia

1.2 A Brief History of Carpets

1.2.1 Pazyryk Carpet- Kasra Carpet

1.2.2 Classifying Carpets- Garden Carpet as a Precedent for This Research

1.3 Relationship Between Carpet design and Architecture

\section{Part II . Exploring the Carpet; Design and Structure}

2.1 Worldviews -Through a Study of Carpets

2.2 Weaving In the Greek Society

2.2.1 Weaving Their Cities

2.2.2 The Greek Understanding of Cosmos through Their Craft

2.3 Persian Carpet; Reflection of Persian Worldviews

\section{Part III . Persian Carpet as a Heterotopia}

3.1 Desire for a "Place"- "Site" Within Carpets

3.2 Relationship between Persian Carpet and the Notion of Heterotopia

Part IV . Proposed Architectural Project

4.1 Site

4.2 Process and Design

\section{Conclusion}

Bibliography 
$1 \quad$ Pazyryk Carpet, More Oriental Rug Notes by Barry O'Connell ON. 10 October $2006<$ httpwww.persiancarpetguide.com>

2 Detail of Pazyryk Carpet, More Oriental Rug Notes by Barry O'Connell ON. 10 October $2006<$ httpwww.persiancarpetguide.com>

3 Medallion Carpet, $19^{\text {th }}$ Century Iran, Oriental Rugs Volume 2 Persian, 1981,Battenberg Verlang, Munich

4 Geometric Design Carpet, $17^{\text {th }}$ Century Iran, ON 10 October 2006 $<\underline{\text { www.toranahouse.com/persian }}>$

5 Detail of a Hunting Carpet, $15^{\text {th }}$ Century Iran, Bloom Jonathan, Islamic Arts 1997,Phaidon Press Limited, London,

6 Garden Carpet $18^{\text {th }}$ Century Iran, Time line of Art History, ON March $2007<$ www.metmuseum.org >

7 Prayer Carpet $16^{\text {th }}$ Century Iran, Bloom Jonathan, Islamic Arts 1997,Phaidon Press Limited, London,

8 Floral Carpet $19^{\text {th }}$ century Iran, ON March 2007, Oriental Rug Gallery $<$ www.internetrugs.com $>$

9 Structure of a Loom, Jole, Iraj, A research on Persian Carpets Tehran, Yasavoli, 2004,

10 Post and Beam Structure of the Greek's Temples, McEwen, K, Indra Socrates Ancestors, An Essay on Architectural Beginnings London, Cambridge, The MIT Press, 1993

11 Site Plan of the Hasht behesht Garden In the City of Isfahan, SamiAzar, Ali Gardens of Iran: Ancient Wisdom Tehran, Iranian Institute for Promotion of Visual Arts, 2004

12 Garden Carpet, Wagner Collection, Bloom Jonathan, Islamic Arts 1997,Phaidon Press Limited, London

13 Garden Carpet, $14^{\text {th }}$ century Iran, Classic Persian Carpet Design, ON March 2007 <www.toranahouse.com/images> 
15 Collage 1, Juxtaposing myself with the space of a garden carpet, By author

16 Collage 2, Juxtaposing myself with the space of a garden carpet, By author

17 Collage 3, Juxtaposing myself with the space of a garden carpet, By author 38

18 Garden Carpet, From Wagner Collection, Bloom Jonathan, Islamic Arts 41 1997,Phaidon Press Limited, London,

19 Conceptual Drawing a \& b , By author 42

20 Aerial Photo of the Site and Neighboring Context, By author 48

21 Photomontage of the Site, By author 49

22 Drawing of the Luna Park Based on my memories, By author 49

23 Site plan, By author $\quad 50$

24 Site Plan, with the Proposed Project In It, By author 51

25 Sectional Drawing, By author 52

26 Interior of the Bazaar Space, By author 54

27 First Floor Plan, By author $\quad 55$

28 Axonometric Drawing, By author 56

29 Exterior View of the West Elevation, By author 57

30 Front Elevation( South Elevation), By author 59

31 First Floor Plan, By author 60

32 Sectional Drawing-1, By author 61

33 Section -2, By author $\quad 62$

34 Second Floor Plan, By author 62

35 West Elevation, By author 63 
36 Third Floor Plan, By author

37 Sectional Drawing- 3, By author $\quad 64$

38 Fourth Floor Plan, By author $\quad 64$

39 South Elevation, By author $\quad 65$

40 South West Axonometric Drawing, By author 66

41 South East Axonometric Drawing, By author 66

$\begin{array}{lll}42 & \text { West Elevation, Night View, By author } & 67\end{array}$

$\begin{array}{lll}43 & \text { Exterior Front View, By author } & 67\end{array}$

44 Interior View of the Bazaar Space From The Entrance, By author 68

45 Interior of the Bazaar and the Vestibule Area, By author 69

$\begin{array}{lll}46 & \text { Interior View , By author } & 70\end{array}$

47 Axonometric View of the Overall Structure, By author 70

48 Axonometric View, By author $\quad 71$

49 Interior view of the Bazaar Space, By author 71

50 Interior view of the circulation, Space attached to the Facade., By 72 author

51 Exterior view, North west Elevation from Chamran Highway, By author 73

52 Final Presentation Panel, By author $\quad 74$ 


\section{Introduction}

Iranian art and culture has manifested itself in variety of ways throughout its ancient history. The many different and shared experiences are expressed through a multitude of Persian arts and literature. The wide and meaningful expanse of Iranian art and architecture has continually set the stage for Persian culture to express itself within the arts of this region. For the purposes of this investigation, the long-standing tradition of the Persian carpet will act as the spatial, temporal, and material embodiment of mythological and cultural expressions that will further inform a proposed architecture.

"It is the peak of Persian creativity, in which the gentlest melody of nature and love of life, inspired by Iranian mysticism, is most coherently revealed. Persian carpets are an interpretation of meaning of life for Persians - man's destiny, beginning and end, paradise and eternity- and manifestation of the heavenly realm on earth, which is the result of progress of love that is merged with hope." 1

The art of carpet weaving is one of the finest manifestations of Iranian beliefs in terms of both meaning and form and is the guide for this thesis.

This research was begun by a study of carpets (as a craft) created in pre classical time within Persian and Greek societies; the founders of this art. Through the study of this artifact, I discovered that each of these two civilizations were inspired by and reflected on this art very differently.

\footnotetext{
${ }^{1}$ Reza Sami-Azar, Gardens of Iran ,Ancient Wisdom, New Visions, (Tehran :Tehran Museum of Contemporary art, 2004) p 8
} 
In ancient Greek society ,craft was understood as indissoluble in the community, and it reflected their understanding of the kosmos. ${ }^{2}$ For them the cosmos was understood through their artifacts such as woven textiles, music, dance, architecture and tragedy, because it was flawless, harmonious and highly ordered. The Greeks understood the structure of the woven textile, and reflected that understanding in their architecture and urban planning. Within Greek society, any analysis of a woven textile and any transformation of their views on this craft was rational and logical. Therefore making of the craft was perhaps a cathartic experience.

By comparison for the Persians, carpets were about the imagery, representation of a space, and the love of nature and life. Their philosophy towards carpets involved emotions, and feelings; an expressive art.

This thesis explores the two world views in Persian and Greek society through the specific study of carpets. It concludes by analyzing the carpets in Western philosophical terms as "heterotopia" as discussed by Michel Foucault. Ultimately the Persian carpet is introduced as a heterotopia in the last chapter.

The main focus of the thesis is on the Persian world view and the study of garden carpets as a representation of a "place" - paradise. In the article Of Other Spaces, Heterotopia, Michel Foucault introduces the Persian Gardens as a heterotopia and claims: "as for carpets they were originally reproductions of gardens (the garden in a rug on to which the world comes to enact its symbolic perfection, and the rug is a sort of garden that can move across space). The garden is the smallest parcel of the world and then it is

\footnotetext{
${ }^{2}$ Indra Kagis McEwen, Socrates' Ancestor, An Essay on Architectural Beginnings, ( London, England: MIT Press, 1993) p 130
} 
the totality of the world. The garden has been a sort of happy, universalizing heterotopia since the beginning of antiquity". ${ }^{3}$

Foucault's heterotopian explorations are a relevant source in the investigation of Persian world views and cosmology expressed through the carpets. Common themes of garden carpets and heterotopia will be discussed in chapter three, where many design criteria were developed. The Greek understanding of textile artifacts also influenced some of the design principles for the thesis' proposed architectural project. The design part of this thesis reflects on the two world views explored, and makes parallels to the ideas of heterotopia. This is done through the exploration of programs, site selection, and key architectural movements that reflect Persian and Greek ideologies regarding carpets; ultimately reflecting the idea of heterotopia within the city of Tehran.

The site is located in Tehran, the capital of Iran in an area where once stood the biggest amusement park (Luna Park) in the city. In other words, before its dismantling in 2006 this site was acting as a heterotopia within the city of Tehran. The proposed architectural project is initially an architectural competition in Iran, and it is an International Persian Carpet Trade Centre, whose main programs are to include a central bazaar, exhibition spaces for coloring and weaving, a theater space, a series of administration spaces, a library and a tea room. Therefore the selection of the programs and the composition of them within the building as well as implementing certain architectural movements that are inspired by garden carpets will also convey the notion of heterotopia within this building.

\footnotetext{
${ }^{3}$ Michel Foucault Of Other Spaces, Heterotopias, Architecture Movement October, 1984, p 6
} 
As discussed, the thesis will introduce the reader to the history of carpets and relevant precedents of this art; second the thesis will compare and contrast the two world views of Persian and Greek culture from pre classical time through study of this craft within their societies. Third the Persian carpet will be introduced as a heterotopia, and common themes between carpets and heterotopian space will be discussed and analyzed. The last section of the thesis will be dedicated to the design project, and the principles that led to the design of the International Persian Carpet Trade Centre, and demonstrate carpet exploration as a relevant source for the making of architecture. 
Chapter 1 .

The Art of Persian carpet

\subsection{Carpet as a Sacred Art of Persia}

The carpet is one of the finest and most exquisite forms of Iranian expression of its' culture and world views. Some of today's remaining examples are amongst the highest quality attained by mankind in terms of their designs, colours and weaving techniques. To this day, the Persian association within the hand woven carpet is as strong as ever, though Iranians are increasingly being swallowed in the whirlpool of a fast expanding industrial, urban society. Without it, an Iranian home is barren and soulless. They are a reflection of the deep rooted bond between the people and their national art. By tracing the history of the Persian carpet, we can see the cultural evolution of a great civilization. Carpets can be seen as simply an artifact of need; as pure and as simple as a floor entrance covering, providing warmth to the nomadic tribesmen. To the majestic beauty of carpets adoring the buildings of Kings and Noblemen, signs of their sovereignty and wealth, carpets are a symbolic reflection of Persian beliefs.

Today the Persian carpet is associated with luxuriousness; a marked contrast with it's utilization among the nomadic tribes who wandered the great expanse of Persia in search of their livelihood. It was an object of necessity to keep them warm, and it was perhaps out of this necessity that they developed it into art. Through use of bright colours and varying forms the lives and world views of these tribesmen were metaphorically captured through the carpet. Aside from being an article of furniture, the carpet was also 
a writing form for these people; recording their fortunes, life narratives, cosmologies, and beliefs. ${ }^{4}$

\subsection{A Brief History of Carpets}

Due to its long and historical development, Persia (modern Iran) has had a significant role in the Middle East region in the development of many art and craft techniques. The art of carpet weaving is one of these techniques. According to historians, the history of weaving and the designing of carpets goes back to the year1000 BC.

Similar to other cultures various kinds of arts are developed based on their necessities in societies. This is also the case for the Parisian carpets. Along with necessity-individuals needed to embody their cosmological view in the artifacts that meant the most to them. The creative activity of weaving evolved in unison with the culture and worldview of the people living in a highly inspirational and characteristic natural world.

\subsubsection{Pazyryk Carpet- Kasra Carpet}

One of the oldest Iranian hand woven carpets in the world depicts symbols and representations of people and animals. It dates back two thousand four hundred years ago and is called the Pazyryk carpet. ${ }^{5}$ In 1949, this earliest recognizable Persian rug was discovered by the Russian Professor Rudenko while excavating burial mounds in the Altai Mountains of Siberia. The rug was preserved purely by coincidence as the carpet

\footnotetext{
${ }^{4}$ Iraj Jole, Research On the Persian Carpet ( Tehran: Yasavoli Press, 2004) P 15

${ }^{5}$ Iraj Jole, Research On the Persian Carpet ( Tehran: Yasavoli Press, 2004) P 17
} 
had been placed in the burial mound, the water streamed into the mound and froze; therefore, protecting the rug from decay.

This carpet depicts beautiful illustrations of vegetation and symbols of real and monstrous species (half animal half human), and abstracted images of soldiers dressed in clothes from the Acamenian era. The centre of this carpet is composed of twenty four squares within a rectangle. It is highly geometrical with a systemized order. Supported by the depiction of soldiers in the border, it has been insinuated that it was woven for the king or an important member of the army. Despite its age, it is clear that the Pazyryk carpet is woven by superb workmanship, indicating that the weaving tradition was already established in the region during that era.

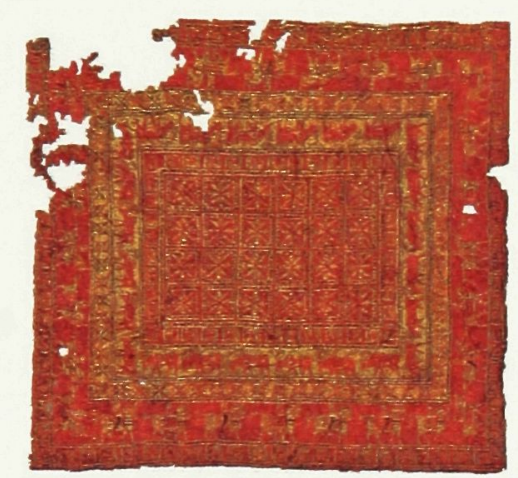

Figure 1, 2 Pazyryk Carpet and a detail of it.

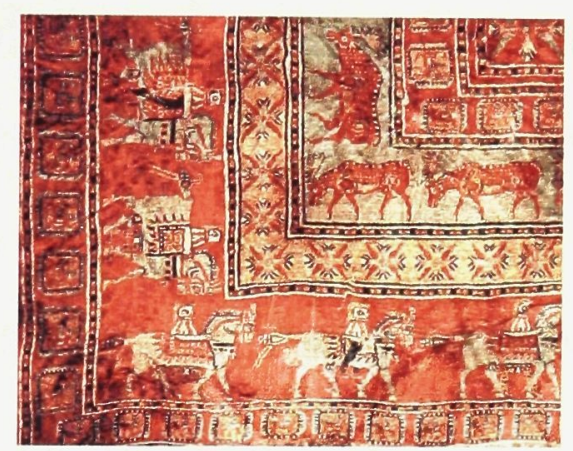

Another important carpet is Kasra Spring (Baharestane Kasra), which was woven for the King of Sasani whose name was Kasra and was displayed in his castle during the winter months. ${ }^{6}$ This carpet was made out of silk and wool and was ornamented with valuable stones. This carpet depicted images of vegetation and flowers, mimicking the feeling of spring. Kasra's spring adorned the King's Momentous space during the winter as a way of nostalgically experiencing spring during the harsh and cold weather.

\footnotetext{
${ }^{6}$ Reza Sami-Azar, Gardens of Iran ,Ancient Wisdom, New Visions, (Tehran :Tehran Museum of Contemporary art, 2004) p 19
} 


\subsubsection{Classifying Carpets - Garden Carpets as a Precedent for This Research}

The beauty and the design of hand woven carpet are dependant upon the materials and techniques used in addition to the carpet designer's skill and imagination which is founded upon their understanding of the world (cosmos) around them. In other words one can argue that different types of carpets are distinguished not only by their various geometrical designs, colures, sizes, knot types, but are also directly tied to each weavers' situatedness within the various tribes and regions. Over time each region creates their own styles, so carpets become very place specific, having a direct impact on material selection and image content.

Through the use of abstracted images, landscapes and gardens, carpets have brought identity, creating roots for all Iranian arts. A Persian carpet is a paridaeza (taken from Persian word Pardis) and is meant to be expanded on the ground, as a metaphorical reflection of the sky or another "place". An illustration of metaphorical and symbolic images on a real, physical, and material carpet, reminds us of the notion of creation, and connects the worldly life to the spiritual and the unworldly one. ${ }^{7}$

I will discuss some of the main categories of carpets in the following, and introduce garden carpets as the main focus of this thesis. Classification of Persian carpets is established on the development of style or design. According to the book called Exploring the Persian Carpet by Toraj Jole, Persian carpets are classified into twenty different categories according to their designs. Six main significant categories introduced

\footnotetext{
${ }^{7}$ Shirin Souresrafil, Book of Iran's Carpet, (Tehran: Fardin Press, 1987, p 32
} 
in the following are such as: animal carpets, geometric, garden, floral, medallion patterns and prayer carpets which were created after the influence of Islam on this region. Later, after the $18^{\text {th }}$ century, the designs of carpets were attributed to specific towns in Iran. For example the City of Kashan became famous for their floral design and Qum for its prayer carpets, a directed relation to the City's religious background and population. ${ }^{8}$ Though all in all, these different designs are still suggestive of one common ideology, which is the representation of paradise, or another place beyond the earthy space.

Medallion design is based on a systematic or modular rotation of a pattern or form from the centre of the carpet to the outside borders. ${ }^{9}$ The centre is therefore the dominant feature, and other patterns extend out from it. Basically the carpets' design is dominated by a single symmetrical centre piece that is usually a representation of a pool of water. This term, however, is also given to carpets where their patterns consist of several forms and rows of medallion figures.

Geometric designs are usually inspired by architectural spaces, and are often representations of specific buildings, such as certain mosques or palaces. With the addition of detail elements added, these carpets are meant to look heavenly and/or supernatural. $^{10}$

Animal Carpet is the representation of a hunting space. ${ }^{11}$ These spaces usually represent the power of humans over animals and can be clearly observed, through the

\footnotetext{
${ }^{8}$ Iraj Jole, Research On the Persian Carpet ( Tehran: Yasavoli Press, 2004) P 45

${ }^{9}$ Sooresrafil, Shirin Persian Carpets (Tehran, Nashr Press, 2003) p 15

${ }^{10}$ Ibid $\mathrm{p} 16$

${ }^{11}$ Iraj Jole, Research On the Persian Carpet ( Tehran: Yasavoli Press, 2004) P 45
} 
interplay of exaggerated scale and juxtaposition of images. In these carpets the hunter is shown in various positions hunting different animals that are usually distorted in their scale (animals in juxtaposition with human body are illustrated in a scale of hierarchy). The final type is the garden carpet, which suggests spaces that are imitations or representations of Persian gardens with their earthly quality ideally abstracted. ${ }^{12}$ They are perfected representations of three dimensional spaces within the material, two dimensions of the carpet.

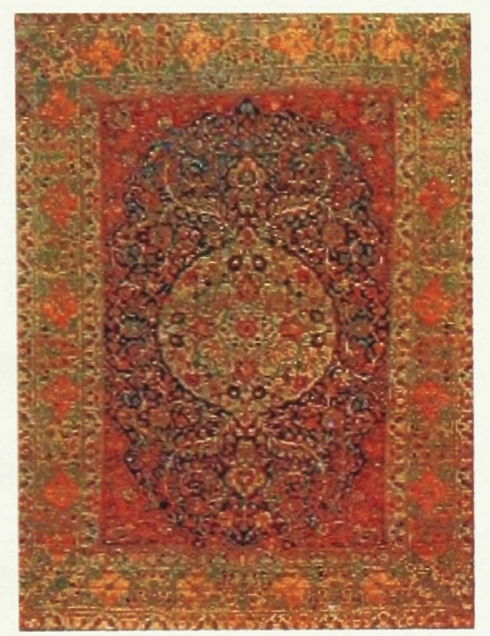

Figure 3. Medallion Carpet from $16^{\text {th }}$ Century

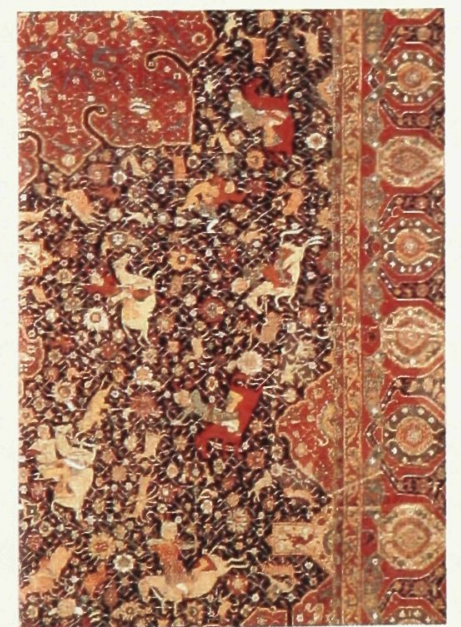

Figure 5 Detail of a Hunting Carpet, $15^{\text {th }}$ Century

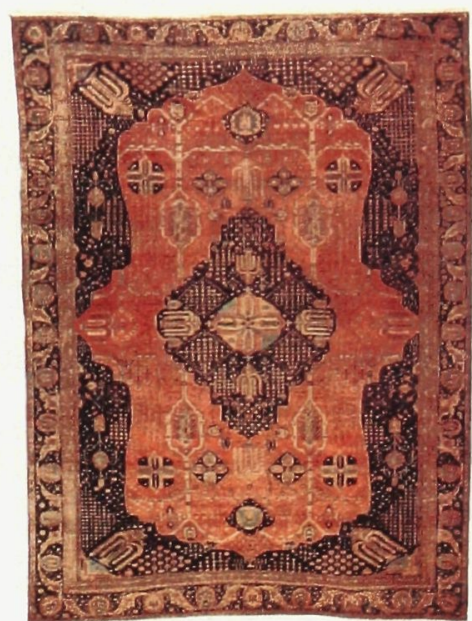

Figure 4 Geometric Design Carpet from $17^{\text {th }}$ Century

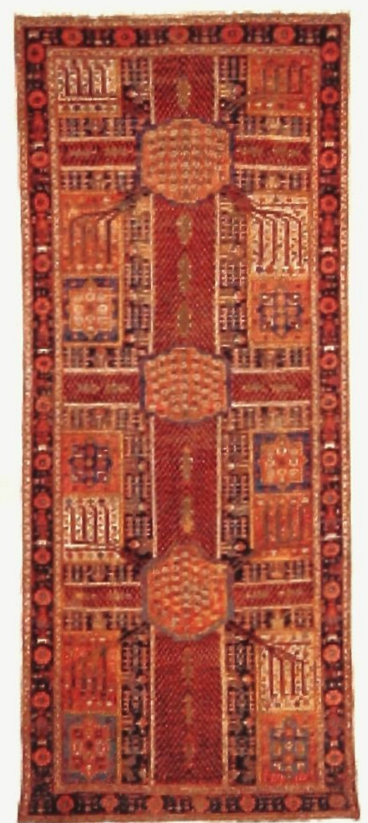

Figure 6 Garden Carpet $18^{\text {th }}$ Century

\footnotetext{
${ }^{12}$ Ali Hassuri, Gardens of Eden and Persian Carpet Design, Iran Rugs June 2002 No23
} 


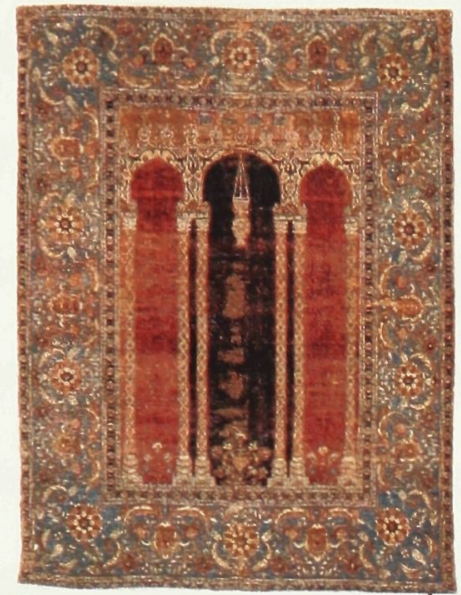

Figure 7 Prayer Carpet, $16^{\text {th }}$ Century

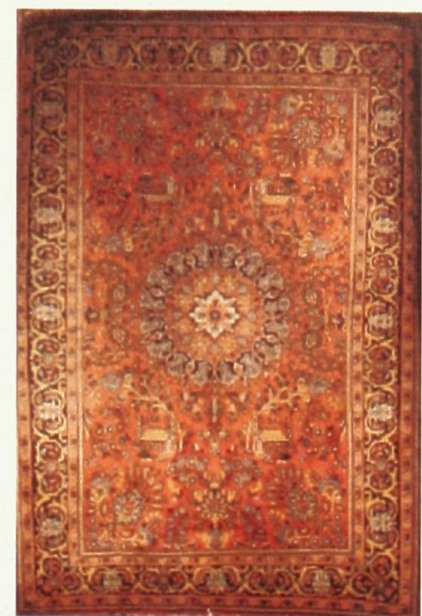

Figure 8 Floral Carpet, $19^{\text {th }}$ century

\subsection{Relationship between Carpet Design and Architecture}

The images of walls and borders woven on to the carpets are representative of the walls around in gardens. Similar to architectural spaces, the walls around the garden carpet separate the interior from an exterior (heavenly from worldly, sacred from profane). The threshold (entrance) condition becomes a significant element. In carpets walls are illustrated in such a way that the entrance to the space of the garden carpets is hidden. This is suggestive of the effort one should make in entering the space of a garden. ${ }^{13}$ Therefore, there is a close relationship between garden carpets and architectural spaces. The element of wall or border is always present; a direct relationship to a significant architectural element in their cities since the pre historic time. Elizabeth Moynihan, the author of Paradise as Garden elaborates: "Ruins of settlements of the sixth millennium in Persia have been uncovered and found to have had massive defensive mud walls. Within the security of their walls, their supply of water assured, the people were free to worship the symbol of their gods." 14

\footnotetext{
${ }^{13}$ Iraj Jole, Research On the Persian Carpet ( Tehran: Yasavoli Press, 2004) P 65

${ }^{14}$ Elizabeth B. Moynihan, Paradise as a Garden, (London, Scolar Press, 1979) p17
} 
On the southern province of Parsa (modern Fars) is where the Aryan Achaemenian society settled, and this region was known to the Greeks as Persis (Persia). The history of Persian gardens started with Achaemenian, during this time, and the greatest gardens of the ancient world were created at that time. Moynihan claims that one can speculate how Cyrus (the Acadian king of Persia) used his gardens, but that there is evidence to suggest that these gardens were meant to be viewed from the airy buildings rather than enjoying them as a place for activities. They were considered sacred. ${ }^{15}$

The art of architecture in Persia begins with the construction of buildings out of simple brick works, which later led to colorful, geometrical, image based ceramic and tile work. During the Islamic era (arrived in Persia c. 600 AD) Iranian culture and arts were drastically transformed by this new zeitgeist. Not only were new art compositions were created, but such things as architectural spaces, and carpet weaving were directly influenced by the theories, ideologies and new meanings associated with the Islamic religion.

The mystical relationship between Iranians and their gardens -and how they nurture them with water, trees and flowers - shows that the garden (and carpet as an imitation of it) is a sacred realm. Gardens create a relationship between an earthy and a heavenly realm; the real and the imaginary. Like many other Iranian arts, Persian gardens have simple plans; almost a child like interpretation of nature that is illustrated through chaharbagh (four section garden). The question of why the paradigm of the carpet was

${ }^{15}$ ibid 21 
the source of inspiration for all Persian arts is a critical one leading to whether it can still act in a generative role for the design portion of this thesis.

The carpet has been a direct inspirational source for the development of Iranian architecture; having influences on how the spaces are divided, and how the program is distributed within the building. Daryoush Shaygan, a Persian traditional art critic writes: "the fundamental of Persian architecture is the division of space into four parts, which recalls the archetypal model of the quarto- partite world. All aspects of Iranian art are revelations of heavenly music of the promised paradise." 16

Architecture in Persia has also been inspired by the art of painting, and has resulted in the patterned ceramic works in many architectural spaces as well as in the three dimensional carvings on architectural elements within a space. The art of carpet designing, which is a reflection and expression of architecture, is therefore also inspired by imagery ceramic works. In other words, symbols and images such as Shah Abasi and Niloofar flowers in carpets being next to architectural elements such as walls, floors, columns, and ceilings create a composition of images that are unique and two dimensional, yet inspired by a three dimensional architectural space.

Reciprocally, architecture as a whole or as a component (macro or micro level) has been an inspiring source for the great designers of carpets. The use of Images and symbols creates Persian carpets that are full of life, and the created spaces within a spread of carpet interconnect with real architectural space; vegetation flowing from the ceiling to

${ }^{16}$ Daryoush Shayegan, “The Formative Rhythm of Persian Space” Espace Persan, ( Paris 1986) p112 
the walls and from the walls to the floors. The sacred art of the carpet becomes the essence of all the valuable arts of Persia (architecture- painting- ceramic work and sculpture) and despite their unique differences and individual qualities, the carpet unifies all of these expressions within a single stretch of fabric. 
Chapter 2.

Exploring the carpet; Design and Structure

\subsection{Worldviews- Through the Study of Carpets}

The art of weaving, and carpet designing has been a tradition for Persian, and Greek societies established in the early part of their civilization. For the two, the art of weaving has been a fundamental element and respected expertise within their societies especially in the pre-classical time. However their approach to- and final expressions of it- have taken different directions. In other words they both have taken inspirations from very specific yet different sources, and have reflected on their methods and manners of weaving and making the craft in various ways. This chapter will discuss the two different worldviews of Persian and Greek cultures by looking at the art of carpet within their respected society. Studying this art can help us understand some of the main cultural visions of these two civilizations that can acknowledge the way they conceive the word around them. This thesis will discuss the differing influences that helped in shaping of this craft for the two cultures. The Greeks having gotten theirs from the technical and structural aspects of weaving carpets, while, the Persians having gotten their inspiration from cultural ideologies, aesthetic design, and the mode of their representation on carpets themselves. In both cases, having a direct reflection in the development of architecture will also be discussed. Indra Kagis McEwen's book $\underline{\text { Socrates Ancestors, }}$ associates the act of weaving and textile crafts as an influential element of "architectural beginnings" in Greek society. ${ }^{17}$ Both civilizations wove their ideas, narratives, thought, and cosmologies into their carpets and textile artifacts. The Greeks were influenced and later

\footnotetext{
17 Indra Kagis McEwen, Socrates' Ancestor, An Essay on Architectural Beginnings,( London, England: MIT Press, 1993) Back Cover
} 
expressed their cosmology as being a more rational way of thinking. The Persians, on the other hand, demonstrate their cosmology as a more emotional and expressive way of looking at the world contiguous with all other arts. Both of these views will have a direct influence in the design component of the thesis. In order to carefully and rigorously explore these ideological positions, the thesis will divide the study of carpets into two sections. One will consider the structural aspect of carpets and weaving, the other will explore the expressions they hold, the imagery and their representation within the carpets. The following is a discussion of the two different world views based on the study of weaving, and carpets.

\subsection{Weaving In the Greek Society}

In this discussion, Greek methodologies, inspirations (such as the structure of a woven textile and loom), and their influences in their architecture and urban planning are compared to the Persian cosmology and worldview reflected in carpet designs. For the Greeks the important significances were the very act of weaving and the bonding of the knots, itself the structure of a woven cloth, and the loom. These meanings were translated and visible in the development of their city planning, and their architectural spaces and structural development of their architecture. As mentioned, For the Persians, it appears that their carpet development and representation came from an expressive and emotional relationship to the world: the idea of paradise, the garden, and carpet as a symbol or representation of another world.

McEwen talks about craft as an indissoluble element in the Greek community and western philosophy in pre classical time, and introduces them as architectural 
beginnings ${ }^{18}$. In the following, I elaborate on some of her ideas and understandings on the meanings of craft, the act of weaving and textile artifacts. I begin with talking about the etymology of the word "weaving" by studying the roots and meaning of this word we can perhaps find out about their vision towards woven crafts that will help us draw conclusion about their analytical view of the world.

The word weaving or in Greek, hyphainein ${ }^{19}$ has a rational origin for Greek. The word weaving meant bringing into kosmos (cosmos), bringing into life or light, and making the woven visible. ${ }^{20}$ McEwen interprets it even more, stating: "Craft (textile) gives things life, and it is no accident that (weaving) is to give birth, to build and to letting appear"21 Therefore the Greek's rationality makes a strong connection between the act- or the ritual of weaving -and the meaning of the word. As mentioned earlier, the loom also had a special significance on ancient Greek society. Histos is used to define loom, and it means anything that is generally set upright ${ }^{22}$. The Greek loom is generally a vertical one, and it acts as a structure to hold the textile that is being woven on the loom. Weaving textile was to create a skin, a surface or an appearing, therefore this ties back to the notion of bringing the craft into light, and making it visible using the upright vertical loom as a structure. McEwen looks for more evidences to rationalize the origins of the meaning of the loom and she claims that Histos comes from the word Hestia which

\footnotetext{
${ }^{18}$ Indra Kagis McEwen, Socrates' Ancestor, An Essay on Architectural Beginnings, ( London, England: MIT Press , 1993) p 130

${ }^{19}$ Ibid p 54

${ }^{20}$ Ibid p 54

${ }^{21}$ Ibid p55

${ }^{22}$ Ibid 101
} 
means hearth; a feminine word that means "I set up",23. Therefore the word Histos (loom) derives from Hestia (Hearth) and it is clearly an object that was mostly used by women. As McEwen says: "it was an essential constitution of every Greek Household." ${ }^{24}$ It appears that for Greek society the household (as the owner of the loom) and the loom itself somehow shared the same identity. One of the first things a Greek child saw when he began to see all, was his mother, and the next thing he saw was his mother weaving. ${ }^{25}$ Weaving was one of the few activities compatible with simultaneous child watching in Greek ancient society. Small children watched their mothers ceaselessly weaving on upright looms that must have seemed monumental to them. ${ }^{26}$

McEwen makes more connections on the act of weaving to femininity and she brings up stories from Homer to clarify this idea. In the Iliad, according to Homer, it is said that Hera wears her well crafted clothing in order to be able to appear in society ${ }^{27}$. For the Female therefore, the woven textile which they wore had metaphorical meaning of appearing in society, or appearing to dance. McEwen elaborates on this story and says: ". . . where female divinities adorn themselves, or, as Homeric language actually describes it, wrap themselves in kosmos, in order to go dancing, the suggestion is that the ordering of the dance is a reflection of their adornment, ordered second skin, and vice

\footnotetext{
${ }^{23}$ Indra Kagis McEwen, Socrates' Ancestor, An Essay on Architectural Beginnings, ( London, England: MIT Press, 1993) p 101

${ }^{24}$ Ibid 109

${ }^{25}$ Ibid 109

${ }^{26}$ Ibid 116

${ }^{27}$ ibid 54
} 
versa." 28 The Greek took the idea of the vertical loom furthermore, and inspired their architecture by the structural aspect of the loom.

"The vertical loom is about the simplest example imaginable of post- and -beam structure. For the Greeks it was certainly the most familiar one. The structure was not significant in itself. That it had been, since time immemorial, the structure of a loom made it so. Structurally, the Pteron of a peripteral temple is all post- and- beam." ${ }^{29}$

Pteron in Greek means something that is intended for displaying in the city, and it appears that the post and beam structure was to make the temple visible just like the loom was meant to make the textile or carpet visible. Therefore we can see how this idea of bringing something into appearance was transformed into the architecture of Greek temples. Inspired by the structure of the vertical looms, post-and -beam soon became columns, which later on were elaborated to have a base, a cornice, or a capital. Post and beam became the main structural element of the Greek temples, and made the temples visible in their cities. ${ }^{30}$ In understanding the relation of the structure of a loom and structure of a building McEwen writes: "A Pteron, in its structural essentials, is constituted as a linked sequence of such frames, where the port of one frame supports not only their own beam but also one end of each of the two beams extending over the frames on either side. Remove two columns two beams collapse, remove a whole frame and, and three looms no longer stand. They were always in use. Weaving the visible city was a

\footnotetext{
${ }^{28}$ Indra Kagis McEwen, Socrates' Ancestor, An Essay on Architectural Beginnings, ( London, England: MIT Press, 1993) p 56

${ }^{29}$ Ibid p 110

${ }^{30}$ Ibid 112
} 
perennial undertaking" ${ }^{\prime 1}$. In addition to that, Vitruvius, in Book II 'De Architctura makes a point on weaving as an architectural gesture in pre historic time and claims: "And first with upright forked props and twigs put between, they wove their walls"32 $\mathrm{He}$ also believes that the structure of a loom and weaving were influential when people started building dwellings in prehistoric time; indicating one of the first architectural structures as the upright Greek loom.

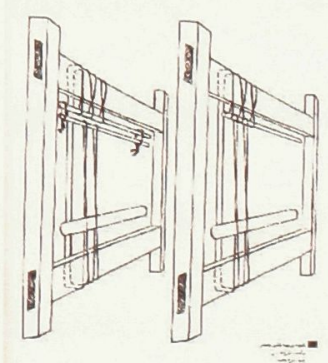

Figure 9, Structure of a Loom

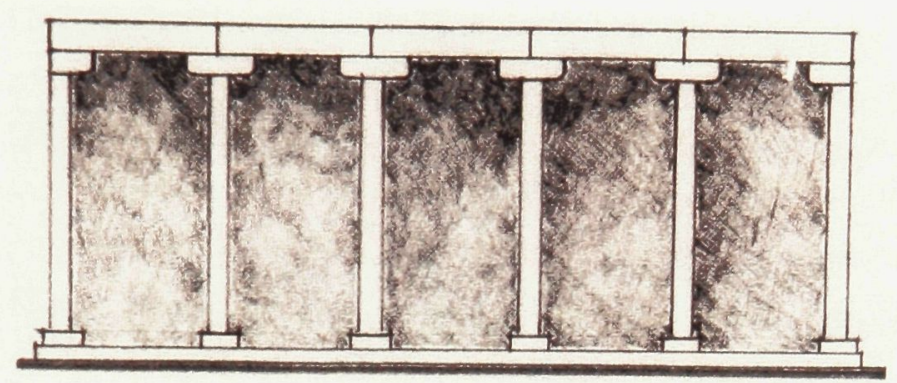

Figure 10 Post and Beam structure of the Greek's Temples

\subsubsection{Weaving Their Cities - City Planning For the Greek:}

In addition to the structure of the loom, the structure of woven textile (carpet) itself had significances in the Greek cities, and urban planning particularly in the seventh and eighth century ${ }^{33}$. The Greeks thought of their cities in terms of weaving, or the orthogonal elements (threads) in a woven textile. ${ }^{34}$ Weaving consists of two perpendicular elements coming together, and so are the streets and roads for Greeks. As McEwen believes there is no doubt that the orthogonal layout of their roads has been inspired by the structure of woven textile. As McEwen says: "weaving consists of the

\footnotetext{
${ }^{31}$ Indra Kagis McEwen, Socrates' Ancestor, An Essay on Architectural Beginnings, ( London, England: MIT Press, 1993) p 111

${ }^{32}$ Ibid p 113

${ }^{33}$ Ibid p 110

${ }^{34}$ ibid p 81
} 
interlacing at right angles, by one series of filament or threads, known as the weft . . of another series, known as the warp, both being in the same place" 35 As mentioned earlier weaving interpreted by Greek was brining into kosmos (cosmos), or making the textile craft appear; applying the same ideology to their urban planning they intended to make their cities visible through carrying the orthogonal grid within the cities. The Greeks made the roads intersect at right angle to mimic the structure of woven textile to weave the surface of the city that come into light along with the activity of its' citizens. By getting inspiration from a woven cloth, western thought has brought up an order based on a square grid (orthogonal arrangement) to avoid chaos within their city and city planning. In other words the Greek "wove" their cities by laying out regularly spaced streets that intersect at right angles; making them visible. Others have also argued that the grid of the city had also to do with orientation of the citizens, the position of the citizens in the city, and the geometric order of the cosmos. However McEwen disagrees with this idea, and takes the argument back to the structure of woven textile, and says: " . . before either the cosmos or the city becomes geometrical, the experience of weavers had already let them to discovery that Kosmos of a tightly woven cloth depended on equally spacing warp and weft threads and interlacing them at right angles."

As discussed earlier, the idea of order and structure in woven artifact is taken beyond the act of weaving by Vitruvius and he compares good architecture to a well woven cloth. In book one, chapter two of De Architecture, Vitruvius discusses that which architecture can depend on. The terms Vitruvius stated in his book are mainly of Greek

\footnotetext{
${ }^{35}$ Ibid 83

${ }^{36}$ Indra Kagis McEwen, Socrates' Ancestor, An Essay on Architectural Beginnings, ( London, England: MIT Press, 1993) 86
} 
origin; words such as taxis (order) and diathesis (arrangement) are discussed in architectural context. McEwen claims there are common elements in a harmonious piece of architecture, and well woven cloths (carpet), and she refers to the word "eurythmia" as the common spirit between architecture and weaving ${ }^{37}$. As McEwen explains the roots of this word; the most straightforward derivation of the word eurythmia is from eu, which means, good or well, and rythmos, which is not only just a regularly recurring motion, but also a shape or a pattern. Therefore the rationality of the western thinker is systematic in making connections between weaving and architecture; both embodying eurythmia.

Having explained this term, for Vitruvius the transformation of this word as the description of a well woven and well fitted cloth to architecture would be the embodiment of the rhythmos in a work of a building. Architecture embodies eurythmia when it is perfectly attuned or adjusted to its surrounding element. ${ }^{38}$ Again, one can see how there are analogous relationships drawn between weaving and architecture. In contrast to this will be discussed in the next chapter, where emotional ideologies and their transformation into Persian art and architecture are discussed through the study of carpet designs.

Another word discussed by McEwen to describe a well woven textile in Greek society is "harmonious". For a textile to be harmonious, it had to be tightly woven. A created artifact was a reflection of the well ordered, and harmonious kosmos, therefore it had to be well built such as in the case of a boat, or well woven (tightly woven) such as in

\footnotetext{
${ }^{37}$ Indra Kagis McEwen, Socrates' Ancestor, An Essay on Architectural Beginnings, ( London, England: MIT Press , 1993) 106

${ }^{38}$ Ibid p 106
} 
the case of a carpet ${ }^{39}$. The idea of a harmonious or well fitted cloth is also translated into the orthogonal method of Greek city planning, especially in the plan of Selinous in Sicily. as McEwen claims: “. . . even as earlier centuries the founders of colonial cities had sought to ensure the harmonia of their new foundation by laying out regularly spaced streets that intersected at right angles." 40

\subsubsection{The Greek Understanding of Kosmos through Their Craft}

"The craftsman let kosmos appear through artifact" $"$. The act of making, during Greek pre-classical time, was concentrated both in the making and discovery of the cosmos. "The dawn of western thought, cannot be understood apart from the craft which was for the Greek, the appearing of Kosmos." ${ }^{42}$ The cosmos was a highly ordered arrangement of their universe, with the craft being the craftsman's interpretation of this order.

Interestingly, Kosmos could also be read as a feminine word, and the word cosmetic in the English language comes from kosmos. As McEwen claims: "for the Greek, when a woman kosmes (adorned) herself, she wrapped her chros in a second skin or body, in order to bring the living surface- body so called to light; to make it appear. If women in ancient Greece were essentially invisible, cosmetic (kosmos) made them visible" 43

\footnotetext{
${ }^{39}$ Ibid p 86

${ }^{40}$ Indra Kagis McEwen, Socrates' Ancestor, An Essay on Architectural Beginnings, ( London, England: MIT Press, 1993 p 85

${ }^{41}$ Ibid 41

${ }^{42}$ Ibid 124

${ }^{43}$ Ibid 44
} 
Weaving, or a woven textile, was a manifestation of harmony, and harmonia was used to describe the order in the nature. The cycles and sequential times in nature such as the number of days (cycle of the sun), the number of months (cycle of the moon), and years (cycle of the season) were all an understanding of harmony and order. The making of artifacts was the manifestation of their understanding of the world. McEwen elaborates on this idea by saying: "It is my contention that, with the dawn of Greek thought, the pattern discovered, or allowed to appear, though making was universalized to become the pattern that eventually came to be understood as the one embodied in the cosmos as we understand the world." 44

Therefore one can observe how elements introduced by McEwen, such as craft, order, kosmos, and harmony all tie together, as they are all interrelated. "In pre classical Greece, harmonia, and its manifestation in political kosmos, were still part of a cosmos understood correctly, through artifacts that held together because of their flawless, perfectly adjusted joints." ${ }^{, 45}$

For the civilization of Archaic Greece, (which we can call western civilization at its roots) the order and arrangement of the world was made to appear through the act of making crafts such as weaving. For the Greek the structure of a woven cloth had more significance as a reflection of the kosmos, or an ordered arrangement, than the designs and patterns on their carpets. Most texts, rarely discuss the imagery and designs of woven

\footnotetext{
${ }^{44}$ Indra Kagis McEwen, Socrates' Ancestor, An Essay on Architectural Beginnings, (London, England: MIT Press , 1993) p 42

${ }^{45}$ Ibid 130
} 
textiles as representation of kosmos. As suggested earlier, regularity in craft and artifacts was manifestation of a highly ordered kosmos. For them, cosmos also meant the things (or cycles) in the nature that revealed harmony and order. "The taxis of chronos reveals custom as necessity insofar as sequential time necessarily makes it assessment of events as repeated or not repeated, as customary or not, as cyclical or not . chronos, sequential time, is the judge- both of heavenly kosmos, and earthly chreon, because it discloses the cyclical, regular movement of celestial bodies." $" 46$

Therefore, in the western tradition, the cycles of the earth (or nature) were the beginning idea of order and harmony, and the Greeks reflect those in their craft by making them ordered and harmonious. In addition to exploring harmony through the structure of a woven cloth, or perhaps even by depicting the geometric shapes within textile artifacts, the Greek represented the order and arrangement of their kosmos. ${ }^{47}$ For them geometry was a form of rationality, and reason ${ }^{48}$, however patterns, shapes, and the representations of imagery in carpets are not the most significant aspect of these artifacts. The design of carpets -by Greeks- is hardly ever discussed in the texts, as their conception of the physical universe was in rational terms. Unlike the Persians, their World was not involved with a World of myth and emotion. "Anaximander thus located the cosmos in a mathematical space composed of purely geometrical relationship."

\footnotetext{
${ }^{46}$ Indra Kagis McEwen, Socrates' Ancestor, An Essay on Architectural Beginnings, ( London, England: MIT Press , 199316

${ }^{47}$ Ibid 42

${ }^{48}$ Ibid 18

${ }^{49}$ Ibid p 15
} 
In comparison to eastern views, Greek world views were based on rationality; a philosophy reflected in their way of approaching the crafts. For Greeks the structure of the loom, the woven cloth, and the logos-centric view of the world were representation of their vision towards the cosmos. This will be contrasted to the notion of "paradise" as the primary inspiration in the craft and artifacts within the Persian culture.

\subsection{Persian Carpet; Reflection of Persian Worldviews}

This part of the essay explores the values and ideologies of the Persian carpet as a reflection of Persian identity and culture; artifacts that demonstrate the notion of the "garden paradise" as structuring a worldview in contrast to the ancient Greek view as expounded above. Through the study of the Persian carpet, one can find out that the origin of this art is instigated by Iranian beliefs, thoughts, and myths. This Persian sacred art is an expressive and representative artifact in the Persian culture, in contrast to the rational thoughts of the Greek craft.

Within each carpet is embedded an intimate, and harmonious relationship with painting, sculpture, and more distinctively architecture ${ }^{50}$. The icons, symbols and narratives within these carpets are rooted in Persian belief systems and mythology with its various influences, and through them the Persian civilization has survived. For the Persians, carpets are about a two-dimensional representation of a three-dimensional space (i.e. garden or paradise) which is surrounded by four walls. In other words carpets are the representation of another world- perhaps a better world, and not an earthly one albeit with reference to geometrics, figural, and material form. Also unlike the Greek they are not

${ }^{50}$ Hassan Makarem, Hearing the Past, Series of Articles, The symbol of Persian Carpet, (Berlin, Gadroon 2005) P 95 
concerned about the structural aspect of weaving, such as the loom, or the orthogonal structure of the fabric. The following is an exploration of Persian worldviews through the study of garden carpets, which as introduced is the main focus of this research. In order to find out more about garden carpets, and the reasoning behind them, a section of the study was directed toward the Persian gardens. A garden pattern in carpets is directly reflected in one group of carpets known as Garden Carpets and in many other ones such as Animal Carpets, or Fish Carpets indirectly. ${ }^{51}$

The garden translated through the carpets is in fact related to the concept of "Paradise". Carpets are some versions of Gardens, but more perfected and more durable than the actual gardens themselves. "These carpets consist of several floral boarders including a wide one full of flowers and trees, and an inner field with stream lattices which is divided by several ponds into four, six, and eight sections each of which are usually divided into another four subsections. ${ }^{, 52}$ The idea of paradise is one of the strongest concepts in Iranian culture and has always been the centre of their ideologies, emotions, and inspirations. In many instances water, fish, and birds became dominant imagery in these artifacts. Persians demonstrated what was in their hearts through the making of such artifacts. The idea of having a carpet on the floor is symbolic of gardens in the interior and a threshold to another world, or the paradise. Some of the earliest examples of these carpets date back to 2000 B.C

Most of the garden carpets that were woven in Iran date back to the Safavid period, and are made in the northwest region of Iran. Interestingly enough, cold and harsh

\footnotetext{
${ }^{51}$ Ali Hassuri, Gardens of Eden and Persian Carpet Design, Iran Rugs June 2002 No23

${ }^{52}$ Ali Hassuri, Gardens of Eden and Persian Carpet Design, Iran Rugs June 2002 No23
} 
climate is a characteristic of this region, and the significance of garden carpets has been perhaps to be a reminder of a more pleasant- spring- condition.

Ali Hassuri a traditional art critic writes in Iran Carpet magazine: "In big carpets, the concept of garden is formed in its most complete way. Here the garden is eternal and everlasting. The garden patterns avoid displaying a real garden, in spite; such gardens reflect the specialties of Persian gardens." 53

The English word "paradise" is basically a translation of the Persian word pairidaeza, referring to a walled garden or a garden carpet. It comes to the western world though Xenophon, the Greek historian, who heard it in 401 B.C. in Persia while fighting with Greek mercenaries. ${ }^{54}$ In Xenophon's Socratic discourse, Socrates explains that the Persian king not only succeeded in the art of war, but also in the art of cultivation; regarding it as a noble and necessary pursuit. "In whatever countries that the king resides or wherever he travels, he is concerned that there are gardens, filled with all the good and fine things that the earth wishes to bring forth, and in this himself spends most of his time, when the season of the year doesn't preclude it",55. In his writing Xenophon used the word paradeisoi for garden, and writes that when Socrates went to Persia, Cyrus (the Acadian king of Persia) showed him his pleasure garden. "He had wondered at it- that the trees should be so fine, the planting so regular, the rows of trees so straight, the angles so finely laid and that so many pleasant scent should accompany them as they walked."56

\footnotetext{
${ }^{53}$ Ali Hassuri, Gardens of Eden and Persian Carpet Design, Iran Rugs June 2002 No23

${ }^{54}$ Moynihan. Elizabeth. Paradise as Garden In Persia and Mughal India, (London Scolar Press, 1982) P 7

${ }^{55}$ Ibid 7

${ }^{56}$ Ibid 10
} 
Xenophon's description of Cyrus pairidaeza, as well as the beauty of his own garden, influenced the design of Greek gardens and the later gardens of Rome.

The geometries of these carpets are influenced by the plan geometries of gardens, which were defined by a decorative, carved stone watercourse (trees and shrubs were planted symmetrically in plots). These were the essential elements in the design of subsequent Persian gardens and carpets, including the gardens of the Islamic world ${ }^{57}$. A mystical feeling for flowers and love of gardens are ancient Persian characteristics. The design of the garden developed and perfected early in the Persian civilization as a manifestation of their taste and needs. In this and as in many other artistic traditions, the Persians were conventional; when a design was "perfected" it was rarely changed. ${ }^{58}$

Woven into these carpets were their beliefs and myths; emphasizing the emotional and expressive aspect of this art because the imagery itself had mythical and symbolic meaning. There is symbolism and myth involved in the representation of a carpet. Every image holds a specific meaning, or is suggestive of a certain mythical and cultural belief. The reverence for water, the mystical feelings for trees, the symbolic division of the earth into quarters by the four rivers of life, and the significance of mountain are among the most ancient and enduring elements of the Iranian traditional art. ${ }^{59}$ It appears that for the Persians the most important is another world, the paradise myth.

The illustrations of paradise in garden carpets also demonstrate the four rivers of life. The division of Earth into four quarters was first associated with kingship around

\footnotetext{
${ }^{57}$ Moynihan. Elizabeth. Paradise as Garden In Persia and Mughal India, (London Scolar Press, 1982) p5 ${ }^{58}$ Ibid $\mathrm{p} 8$

${ }^{59}$ Ibid P 4
} 
2500 B.C, when the Acadian Kings proclaimed themselves as "king of the four quarters" ${ }^{\prime \prime 0}$. In the paradise gardens they reflected this idea with the crossing of the watercourses. This divided the garden, into four sections; believing in its importance because it is a cycle of the four seasons. The division of four was an important characteristic in their ideologies. Reflection of this idea is visible in their urban planning. An example of this is the division of their cities (such as Isfahan) into four, and ultimately locating different groups of people into each of the quarters. ${ }^{61}$

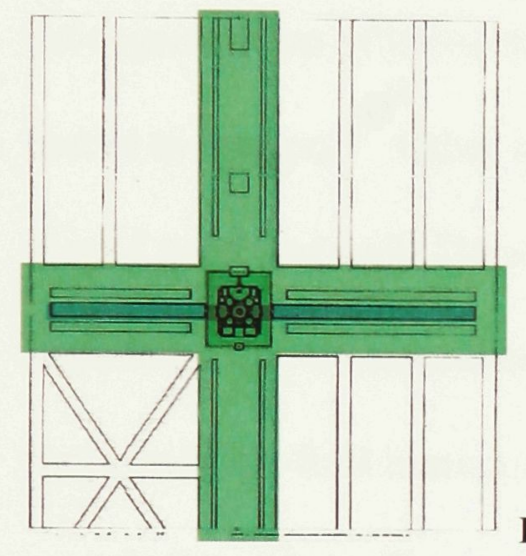

Figure 11 Site Plan of the Hasht behesht Garden In the City of Isfahan

The carpets as I have discussed are therefore representations of another place or space, a "reflection of a higher plane of existence" ${ }^{\prime 2}$. By looking at the manifestations and expressions of paradise in Iranian culture, there are clear connections the design of Persian carpets. Paradise, according to Ali Hassuri, for the Iranians- and since the Bronze Age- was a fenced rectangular garden. This enclosure was designed using seven rows of fences, one of which is thicker and higher in order to prevent the devil from entering "paradise". ${ }^{63}$ These fences are reflected as the borders in the Persian Carpets.

\footnotetext{
${ }^{60}$ Moynihan. Elizabeth. Paradise as Garden In Persia and Mughal India, (London Scolar Press, 1982) p 9

${ }^{61}$ Iraj Jole, Research On the Persian Carpet ( Tehran: Yasavoli Press, 2004) P 75

${ }^{62}$ Nader Arsalan \& Laleh Bakhtiar, The Sense of Unity, ( Chicago and London, The university of Chicago Press 1973) P 9

${ }^{63}$ Ali Hassuri, Gardens of Eden and Persian Carpet Design, Iran Rugs June 2002 No23
} 
Hinted previously through the example of crossing the watercourse, another common element in garden carpets and paradise is the water element; as a never ending stream that always runs in paradise. Water was a central feature in the design of gardens and carpets; the fundamental and most essential element in paradise. For the early civilization of Iranians (Mesopotamian) water was believed as the source of all life, and one of their earliest divinities was the god of water, whom they regarded as their friend and protector and defender of man. ${ }^{64}$ The cosmic tree seen in carpets usually represents the regeneration of immortality, and it is also to symbolize the heavens or a means of ascent to heaven. ${ }^{65}$ Other symbols often represented include the tree of knowledge and tree of good and evil. These signs and symbols show the mythological world view in the experience of Persian culture. Believing in the concept of paradise, in which man transcends his frail human condition, has been a significant part of the Persian philosophy even before Islam. The image of a place of perfection and eternal peace and plenty can make a difficult temporal existence meaningful, and its transitory nature more acceptable for the Persians. The carpet was a representation, and a threshold to that world. They are representations of a different place and act as a reflection of a world of imagination.

${ }^{64}$ Moynihan. Elizabeth. Paradise as Garden In Persia and Mughal India, (London Scolar Press, 1982) P 5 ${ }^{65}$ Ibid p5 


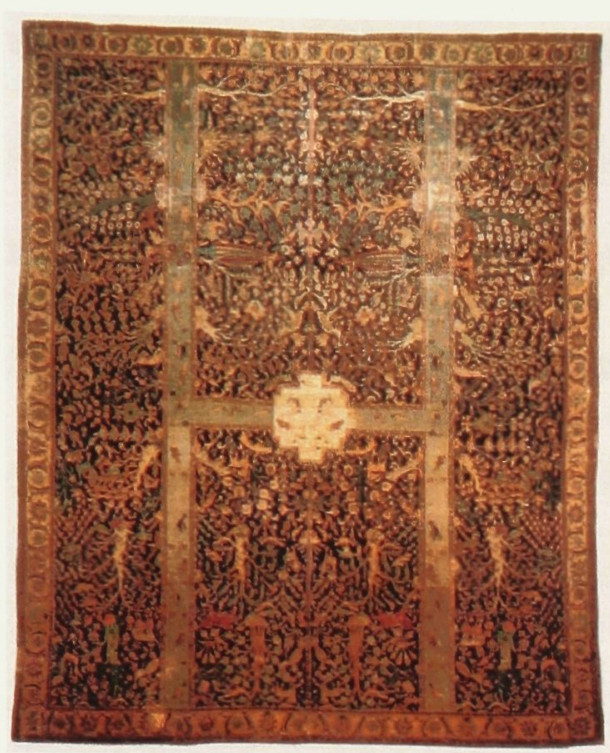

Figure 12 Garden Carpet, $17^{\text {th }}$ Century, Illustration of the Tops view of a garden, Wagner Collection

The trace of nostalgia for paradise also exists in the tradition of the Islamic religion. In the book Paradise as a Garden by Elizabeth B. Moynihan, nostalgic sentiment for paradise is described as “man's repeated attempt to re-establish the paradisal situation lost at the dawn of time, and existed almost in all eastern primitive societies." ${ }^{966}$ For the Persian the representation of a paradise or chahar bagh gardens (four section gardens) in a carpet reaffirms the prevalence of this belief in the "myth of eternal return" ${ }^{, 67}$. Such return can also be found in Indian philosophy, believing that the end of one cycle is the beginning of another. ${ }^{68}$

The paradise promised in the Koran actually consists of several terraced gardens. The garden carpets woven after Islam also reflect this very same idea. As discussed earlier carpets are divided into four main sections, each of these sections containing another seven or eight parts that are representative of these terraces. The gardens were referred to as chahar bagh (four gardens) because they were divided into four, and each

\footnotetext{
${ }^{66}$ Ibid p10

${ }^{67}$ Ibid p5

${ }^{68}$ Ibid p
} 
quarter consisted of another eight divisions called hasht behesht. The number four had a symbolic meaning for Persian as discussed even before the emergence of Islam, and as mentioned earlier it became sacred in other traditional arts such as painting and architecture. In the Islamic gardens of Persia and Mughal India, the terraces were often meant to correspond to the enclosures described in the paradise gardens of Koran. By locating themselves into such ideal gardens and spaces they challenge human feelings, emotion and creativity.

The model for these gardens, "paradise" or the garden of perpetual spring, was the reward of the after life woven into the carpets before and after Islam. These earthy gardens and carpets, and verdant paradise (which affirmed the love of nature) were a celebration of life; reaffirming that the Persians' vision of life symbolically and within culturally defined metaphors and representations. Unlike the Greek, the Persians were more concerned with illustrating or representing their gardens and the idea of a heavenly place through their carpets. Embodying the notion of garden can also be seen in the miniature drawings. Therefore, they were not concerned with the structural studies of a woven cloth as a reflection of their understanding of the world.

Metaphysics of appearance is therefore another key distinction between the two cultures. Persian's wove their cosmology in forms of imagery and illustrations into carpets, while for the Greeks the weaving of the textile and making it appear was a manifestation of their cosmos. 


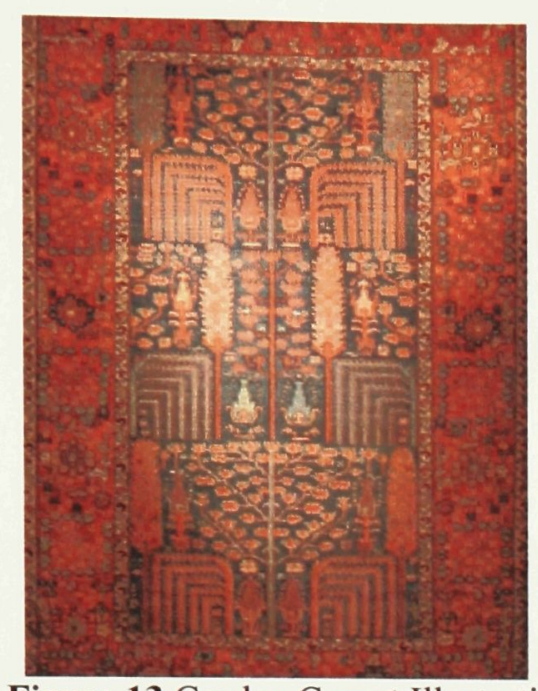

Figure 13 Garden Carpet Illustrating Images of Trees, Water Elements and Birds, From $14^{\text {th }}$ Century

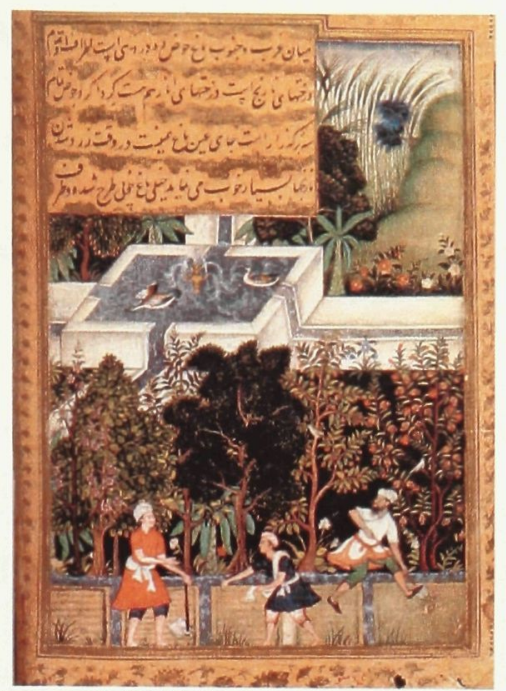

Figure 14 Miniature Drawing. From $15^{\text {th }}$ Century Iran , Embodying elements of a garden

As discussed, every image in a carpet has symbolic meaning; reflecting a notion of Persian cosmology. By depicting the image of symbolic trees reaching over the heavens, or the vision of the purling water and fragment flowers, these carpets never had secular characteristics. The Greeks on the other hand, as discussed in the previous chapter got architectural inspiration from the structure of a loom. According to McEwen, they rationalized the meaning of "weaving" by bringing the textile artifact into light and the cosmos, and simultaneously transformed that idea into their architecture.

Through the study of carpets as textile artifacts within these two societies, two different world views were discovered. For Greeks, the logical analysis of language and roots of their words was influenced by the properties of the woven cloth such as the word weaving and loom as discussed previously. In addition to that, the structure of the loom and textile were the inspiring elements in their architecture and city planning. The Greek's vision of craft (a reflection of their cosmos) was expressed in a logical and rational manner. For the Persian worldview, as experienced through their carpets was to 
be understood as a primarily symbolic and metaphorical one. For them, the carpet is a reflection of paradise (another space) within their physical world. In other words through weaving garden carpets Persians reflected the idea of desire for a "place" or "sites" (as referred to by Foucault) through this art.

At this point I will introduce the Persian carpet as a "heterotopia"69 , and elaborate on this term first discussed first the French philosopher Michel Foucault. The Following are two quotations form the book called Man East and West by Howard L.Parsons that elaborates on further logical Western, and Eastern emotional thoughts.

On western philosophy he writes:

"Western philosophy has proceeded by a strict delimitation of its domain of inquiry, by religious definition of its terms and assumptions, by the unqualified application of rules of logical consistency, and by unflinching and complete analysis of the topic before it." ${ }^{, 70}$ Therefore Logic and logos has been a powerful tool in the West as Parsons indicates. And on eastern way of thinking he argues: "And what about East? For them philosophy becomes a means; exact analysis of limited problems and the rigorous application of logic to certain concepts are never for easterners the goal of philosophy. Rather the goal of philosophy is the goal of human living itself, and philosophy is employed as an instrument to facilitate human fulfillment." ${ }^{, 71}$

\footnotetext{
${ }^{69}$ Michel Foucault Of Other Spaces, Heterotopias, Architecture Movement October, 1984, p 1

${ }^{70}$ Howard L.Parsons ,Man East and West, Essays in East West Philosophy ( Amsterdam, B.R.Gruner, 1975) P47

${ }^{71}$ Howard L.Parsons , Man East and West, Essays in East West Philosophy ( Amsterdam, B.R.Gruner, 1975) P 48
} 


\section{Chapter 3.}

\section{Persian Carpet as a Heterotopia}

\subsection{Desire for a "place"-"site" Within Carpets:}

According to Michel Foucault and his definition of space, we don't live in an empty and homogenous space instead the space around us appears to us from the scope of our imaginations and concerns. It involves our imaginations and dreams, and creates relationships among sites $^{72}$. "We are in epoch of simultaneity: we are in epoch of juxtaposition, the epoch of the near and far, of the side by side, of the dispersed." ${ }^{, 73}$ It seems that the space of our imaginations, and fantasy (for instance the Persian carpet) is considered to be our internal creative thoughts, and in contrast to these spaces there is an outer space or physical world in which we live in. This back and forth between our inner, imaginative space to the physical space, forms new ideas and the potential for creation of imaginative variations of these spaces. Therefore, the representation of a carpet on a two dimensional plane, within a three dimensional space, can create a new interpretation of a site or a place in the viewer's mind. The representation of gardens within carpets acts as an illustration of paradise, in the physical realm. This is introduced to us through Michel Foucault's theory of "heterotopias" first published in an article called Of Other Spaces. This article is in fact based on one of his lectures on Heterotopia. He claims:

"There are also, probably in every culture, in every civilization, real placesplaces that do exist and that are formed in every founding of society- which are something like counter sites, a kind of effectively enacted utopia in which the real

\footnotetext{
${ }^{72}$ Michel Foucault Of Other Spaces, Heterotopias, Architecture Movement October, 1984, p 2

${ }^{73}$ Ibid 1
} 
sites, all the other real sites can be found within the culture, are simultaneously represented, contested and inverted. Places of this kind are outside all places, even though it might be possible to indicate their location in reality. Because these places are absolutely different from all the other sites that they reflect and speak about, I shall call them by way of contrast to utopias, heterotopias." ${ }^{\text {74 }}$ Analyzing this idea within the framework of carpets, makes us aware of a visual and imaginative understanding of carpets as a representation of "a site" or "a place" and its association with the Persian's world view and culture.

As Foucault's argument goes, heterotopia is a site that has no real reference; however it has a reflective and direct relationship with real sites within the society. ${ }^{75}$ Heterotopia can be real or metaphorical site within a society. Heterotopia also happens within real city context as cities also do have metaphorical aspiration for their viewers such as parks and leisure places. Foucault systematically defines heterotopia by explaining what meaning these sites have within society. He breaks down his description into six principles in which he describes heterotopia as a sort of simultaneous mythic and real construction of the space, in which we live in. The notion of heterotopia can be applied to our understanding of the Persian carpet existing within the juxtaposition of the carpet in an architectural setting.

Foucault's elaboration on Heterotopias inspired graphic deliberations in the design proposition. The goal of these exercises was to put myself within the framework

\footnotetext{
${ }^{74}$ Michel Foucault Of Other Spaces, Heterotopias, Architecture Movement October, 1984, p 3

${ }^{75}$ Ibid 3
} 
of the carpet and expressing the idea of creating a heterotopia. This goes back to the initial goal of a Persian carpet which is the creation of a garden (heterotopia) in the secular world and where man locates himself in it.

"I believe that between utopias and these other sites, these heterotopias, there might be a sort of mixed, joined experience, which would be the mirror. The mirror is after all a utopia, since it is a placeless place. In the mirror, I see myself there where I am not, in an unreal virtual space that opens up behind the surface; I am over there, there where I am not, a sort of shadow that gives visibility to myself, that enables me to see myself there where I am absent: such is the utopia of the mirror. But it is also a heterotopia in so far as the mirror exists in reality, where it exerts a sort of counteraction on the position that I occupy., 76

Following exercises are reflections of the same idea.
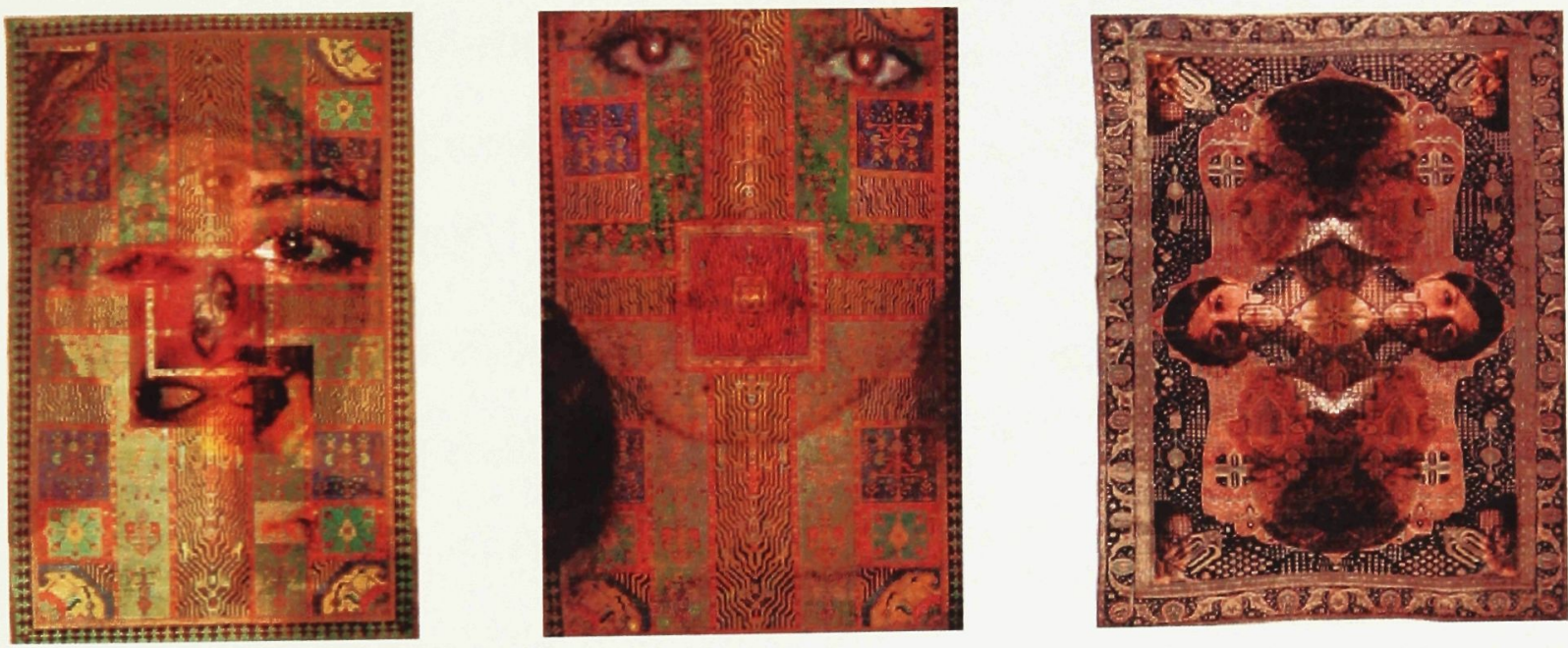

Figure 15, 16, 17 Collages, Placing myself In the space of a garden carpet. Exploring repetition, views, juxtaposition and boarder within the frame work of carpets.

${ }^{76}$ Michel Foucault Of Other Spaces, Heterotopias, Architecture Movement October, 1984, p 3 


\subsection{Relationship between Persian Carpet and the Notion of Heterotopia:}

The following is a discussion on the relationship of the carpet to the idea of heterotopia. Having described the meaning heterotopia within a society, we can now discuss this idea within the settings of the Persian carpet. A Persian carpet could be perceived as the aspiration of a site, because it is a reflection of a place, and reads as an unreal site. Within cities, for instance, the parks, gardens, and leisure places are heterotopias according to Foucault. Therefore they are ambitions of the city and they create juxtaposition while located into the city contexts. The site or a place represented in a Persian carpet does not have a real physical existence beyond that of the carpet itself. Through the metaphorical imagery woven into a carpet, the idea of sublime or paradise has been made possible to be seen or imagined. The garden carpet is a representational embodiment of a place; a paradise. Therefore, by looking at this imaginary site one can find himself in this place or connect to it as if it were a real place. This metaphorical space that is created for the viewer is a heterotopia. The juxtaposition of the heterotopia with the viewer, tries to represent the idealistic and symbolic images through metaphor to the viewer. Just when the viewer is looking to locate and orient himself within this space, he/she becomes aware of their physical absence in that metaphorical space. That is when their mind and their imagination take them towards another world; the imaginary space or site that the carpet holds. Foucault refers to the study of heterotopia as heterotopology and the space we experience that simultaneously constitutes the real and the mythic. ${ }^{77}$

\footnotetext{
${ }^{77}$ Michel Foucault Of Other Spaces, Heterotopias, Architecture Movement October, 1984, p 4
} 
Carpets also create a relationship with architectural spaces themselves; generating a dialog while covering the floors of three dimensional spaces. They construct a metaphorical place that is laid on the ground; suggesting and forcing the viewer into looking beyond their physical existence. "The realization of forms in a traditional society, then, follows the arc of descent from the world of similitude to the temporal world"78 The heterotopic understanding can also be seen in Persian poetry specially those written by Mawlana Jalal-ad-Din Rumi, Persian poet and philosopher of $13^{\text {th }}$ century. He constantly reminds us to be aware of our existence within a higher level. Rumi writes in Mathnavi:

\author{
"I died from mineral, and plant became \\ Died from the plant and took a sentient frame; \\ Died from the beast, and donned a human dress \\ When by my dying did I eér grow less: \\ Another time from manhood I must die \\ To soar with angel-pinions through the sky. \\ Midst angles also I must lose my place, \\ Since "everything shall perish save his face" \\ Let me be Naught! The harp-strings tell me plain \\ That unto him do we return again! "79
}

Rumi is suggestive of another realm of existence through his poetry, and like a Persian carpet, he invites man's imagination to travel beyond his physical, worldly existence.

\footnotetext{
${ }^{78}$ Nader Arsalan \& Laleh Bakhtiar, The Sense of Unity, ( Chicago and London, The university of Chicago Press 1973) P 10

${ }^{79}$ Jalal al-Din Rumi, Mathnawi, 3:218
} 
To further explore Foucault's philosophy the thesis will now analyze heterotopia through the example of a specific Persian carpet. The carpet is called "Baharestane Kasra" meaning, Kasra's Spring, based on Kasra, one of the Kings of Persia during the year 1000 AD. Kasra's Spring was an illustration of spring time and it was meant to cover the king's castle during the winter months as a reminder of the beauty of spring. ${ }^{80}$ This carpet while demonstrating the spring, represented an ambitious site; reflection of a real experience through the winter of the city.

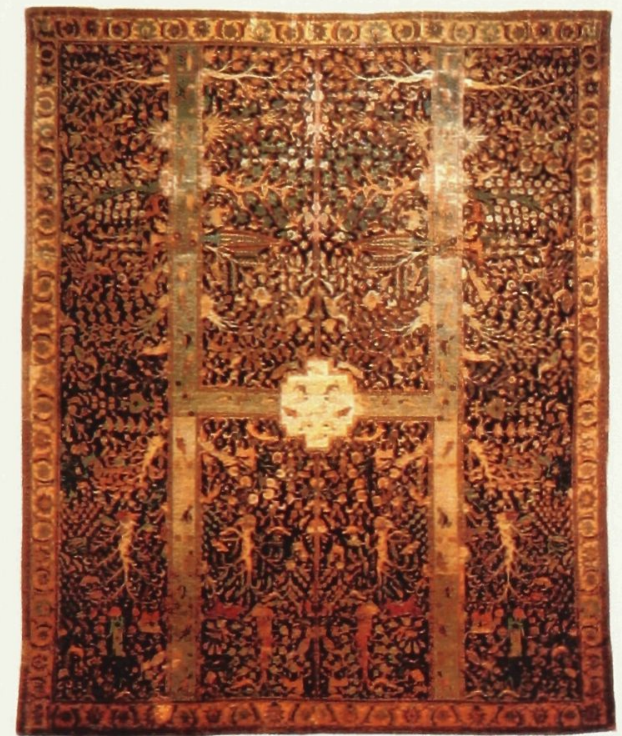

Figure 18 Garden Carpet From Wagner Collection. Illustration of the top view of a garden

The dominant design strategy of the garden carpets is typically an abstracted top view or plan of the garden. However certain elevation views projected from the plans are expressed in different parts of the carpet; usually in the corners or near the edges. A good example of this is the Wagner Carpet from the Burrell collection. The design of this garden carpet is based on a bird's eye view of a garden. The images of walls, vegetation, flowers, and birds in plan are "stylized" to the point of abstraction. The elements juxtaposed against one another are shown in various and distorted scales, which make the

\footnotetext{
${ }^{80}$ Reza Sami-Azar, Gardens of Iran ,Ancient Wisdom, New Visions, (Tehran :Tehran Museum of Contemporary art, 2004) p 19
} 
space of this carpet even more imaginative, and unrealistic. Again, various elements of traditional Persian cosmology are reflected in the carpets such as the water element, and the number of the divisions within this carpet. According to Ali Hosuri most of the carpets woven in Iran including the Wagner Carpet, have seven margins, and one can argue that this is done to connect them to the seven enclosing walls in Zoroastrian doctrines. $^{81}$

In the last part of this chapter the thesis will discus the six principles that Foucault introduced to describe Heterotopias, and attempting to establish clearer connections between this theory and Persian carpet. In addition to that, the thesis will introduce some of the design guide lines that are influenced by the idea of creating a heterotopia through the thesis' architectural proposition for the city of Tehran.
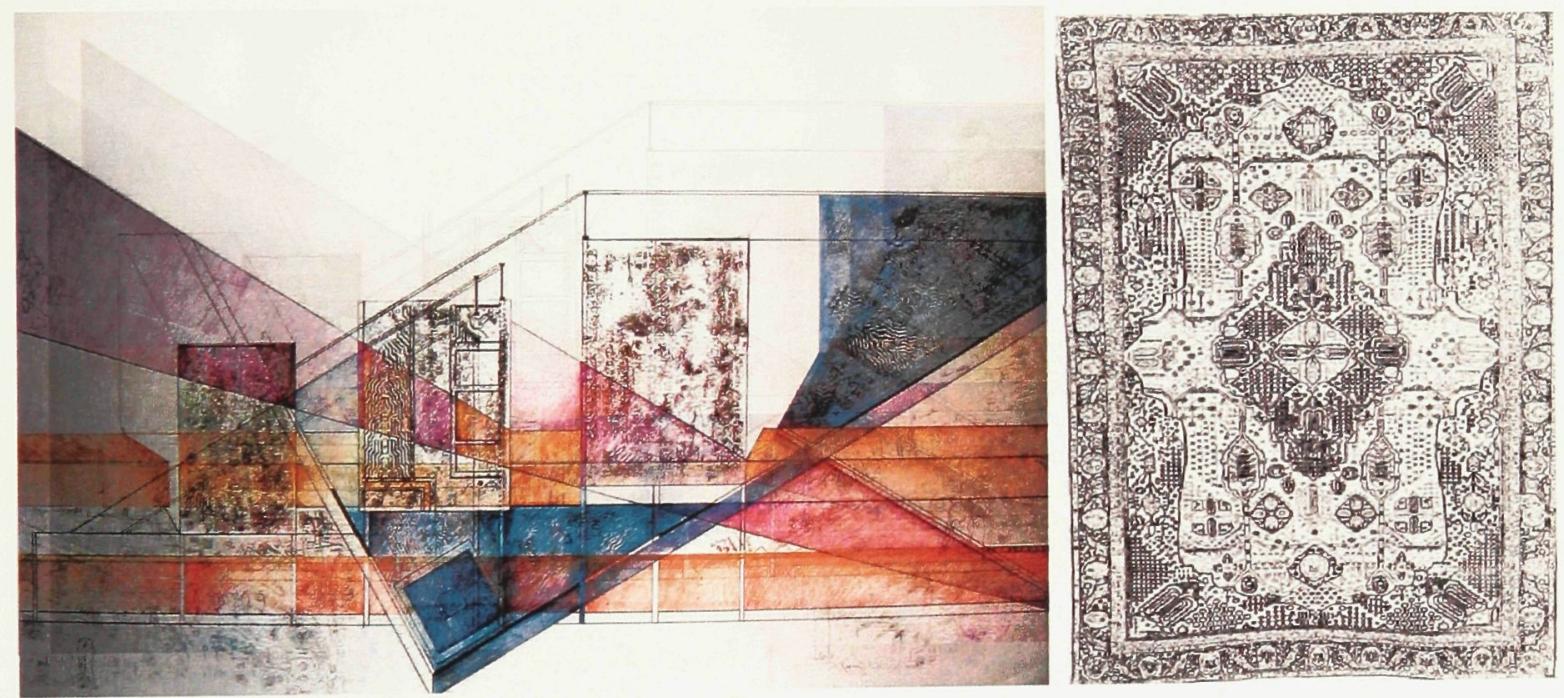

Figure 19.a Conceptual Drawing, exploring elements of heterotopia and garden carpets through drawing. Figure 19.b Line Drawing over a garden carpet.

\footnotetext{
${ }^{81}$ Reza Sami-Azar, Gardens of Iran ,Ancient Wisdom, New Visions, (Tehran :Tehran Museum of Contemporary art, 2004) p 16
} 


\section{First Principle :}

The first principle he introduces is that every single culture in the world constitutes heterotopias of some sort. ${ }^{82}$ Foucault indicates that in the "so called" primitive societies heterotopias are spaces that are privileged or sacred for the people within the society. According to studies done earlier, the Persian carpet, as a reflection of a garden or paradise, is a representation of a sacred space, and therefore Foucault's first principle can apply to this art. Within this first principle he associates places of leisure as heterotopia. "... heterotopias are those in which individuals whose behavior is deviant in relation to the required mean or norm are replaced.. ${ }^{\not 3}$ Therefore inspired by this concept, the program for the thesis project is created within the intent to emphasize their heterotopian possibility.

\section{Second Principle:}

Foucault indicates that in a society, through the changes in the history, the heterotopias can function in a different way ${ }^{84}$. To clear this idea, he gives us the example of the cemetery in western society. Up until the $18^{\text {th }}$ century the cemetery, was placed in the heart of the city, giving it significant importance in western societies. However this has changed. "Western civilization has become atheistic, as one says very crudely, that western culture has established what is termed the cult of the dead." ${ }^{\prime 85}$ Many traditional Persian art-forms incurred dramatic changes, after the introduction of Islam. The Persian carpet is one such example. The carpet as a reflection of paradise was reiterated within

\footnotetext{
${ }^{82}$ Michel Foucault Of Other Spaces, Heterotopias, Architecture Movement October, 1984, p 4

${ }^{83}$ Ibid 4

${ }^{84}$ Michel Foucault Of Other Spaces, Heterotopias, Architecture Movement October, 1984, p 5

${ }^{85}$ Ibid 5
} 
this new religious context. The prayer carpets, which were created during the postIslamic, are manifestations of this transformation. Other changes included new designs that reflected the change in faith-based ideology.

\section{Third Principle:}

"The heterotopia is capable of juxtaposing in a single real place, several sites that are themselves incompatible. ${ }^{, 86}$ In his third principle, Foucault specifically uses the example of a garden to explain his idea because they have superimposed meanings on heterotopia. He says: "the traditional garden of Persians was a scared space that was suppose to bring together inside its rectangle four parts representing the four parts of the world, with a space still more sacred than the others that were like an umbilicus, the navel of the world at its centre (the basin and the water fountain were there); and all the vegetation of the garden was suppose to come together in this space, in this sort of microcosm.. ${ }^{87}$ As for carpets, the same idea applies to them, because they are reproductions and representations of gardens. Next he compares the garden and carpet and writes: "the garden is a carpet onto which the world comes to enact its symbolic perfection, and the carpet is a sort of garden that can move across spaces. The garden is the smallest parcel of the world and then it is the totality of the world. The garden has been a sort of happy, universalizing heterotopia since the beginning of antiquity. ${ }^{, 88}$ Therefore, in case of garden carpets, they are representations of a place within a two

\footnotetext{
${ }^{86}$ Ibid p 6

${ }^{87}$ Michel Foucault Of Other Spaces, Heterotopias, Architecture Movement October, 1984, p 6

${ }^{88}$ Ibid 6
} 
dimensional plane, and the juxtaposition of this plane within a three dimensional space also creates a heterotopia.

\section{Fourth Principle:}

"Heterotopias are most often linked to slices in time." 89 As discussed previously, the Persian carpet is a representation of another place. The paradise promised in Persian culture and Islam relates to a different time than the present, therefore the carpet emphasizes on slices of time, the present and a future. "The heterotopia begins to function at full capacity when men arrive at a sort of absolute break with their traditional time. ${ }^{90}$ As a result of that I believe that the Persian carpet is a good example of breaking with man's traditional time; linking them to a different time and in a different space. The fourth principle will also play a role in the design portion of the thesis. The fourth point starts to make sense within an architectural context as Foucault brings up the library, museum and exhibition spaces as an example of heterotopia. ". . . the idea of accumulating everything, of establishing a sort of general archive, the will to enclose in one place all times, all epochs, all forms, all tastes, the idea of constituting a place of all times that is itself outside of time and inaccessible to its ravages, the project of organizing in this way a sort of perpetual and indefinite accumulation of time in an immobile place, this whole idea belongs to our modernity." "Since the proposed design project will involve exhibition spaces, heterotopia and architectural space will be discussed in the following chapter.

\footnotetext{
${ }^{89}$ Ibid 6

${ }^{90}$ Ibid 6

${ }^{91}$ Michel Foucault Of Other Spaces, Heterotopias, Architecture Movement October, 1984, p 6
} 


\section{Fifth Principle:}

"Heterotopias presuppose a system of opening and closing that both isolates them and make them penetrable. ${ }^{92}$ In this case the walls or the boarder around the garden carpets convey the same idea. Foucault believes that a heterotopic site is not necessarily a freely open space accessible to public, and to get in one must have permission or make a certain gesture. ${ }^{93}$ A garden carpet as an illustration of the top view of garden with four walls surrounded on each side of it, and no apparent entrance shown conveys a scared space to the viewer. Therefore the fourth principle of Foucault, arguing the heterotopian space being not freely an open site is also visible in the garden carpets. Also in relation to this idea, Iraj Jole argues that expressing surrounding walls with no apparent entrance are suggestive of carpets (and gardens) as a sacred space, and in fact the entrances are hidden. ${ }^{94}$ They are visually not really visible, In order to enter into them, one should make an assertive gesture.

\section{Sixth Principle:}

In his sixth principle of heterotopia, Foucault defines heterotopia as sites that can function in two different manners. ${ }^{95}$ The function he introduce that is close to the idea of a Persian carpet is, when the heterotopic site creates a space of illusion; expressing a real space or place. The other one is in contrast to the first one, where the heterotopic site

\footnotetext{
92 ibid 7

${ }^{93}$ Ibid 7

${ }^{94}$ Iraj Jole, Research On the Persian Carpet ( Tehran: Yasavoli Press, 2004) P 60

${ }^{95}$ Michel Foucault Of Other Spaces, Heterotopias, Architecture Movement October, 1984, p 7
} 
creates a space that is another real place. ${ }^{96}$ In the following chapter I will make connections between the ideas discussed above to the design, and introduce the guidelines that informed the decisions for the design features of this project. 


\section{Chapter 4. \\ Architectural Project}

\subsection{Site}

In the following chapter, I will describe the design portion of this project. The guidelines used in the design are based on the ideas, theories, and observations on the carpets that were discussed in the previous chapters. As indicated earlier, the site for the proposed architectural project is located in Tehran, the capital of Iran, and the program for it is an International Carpet Trade Centre.

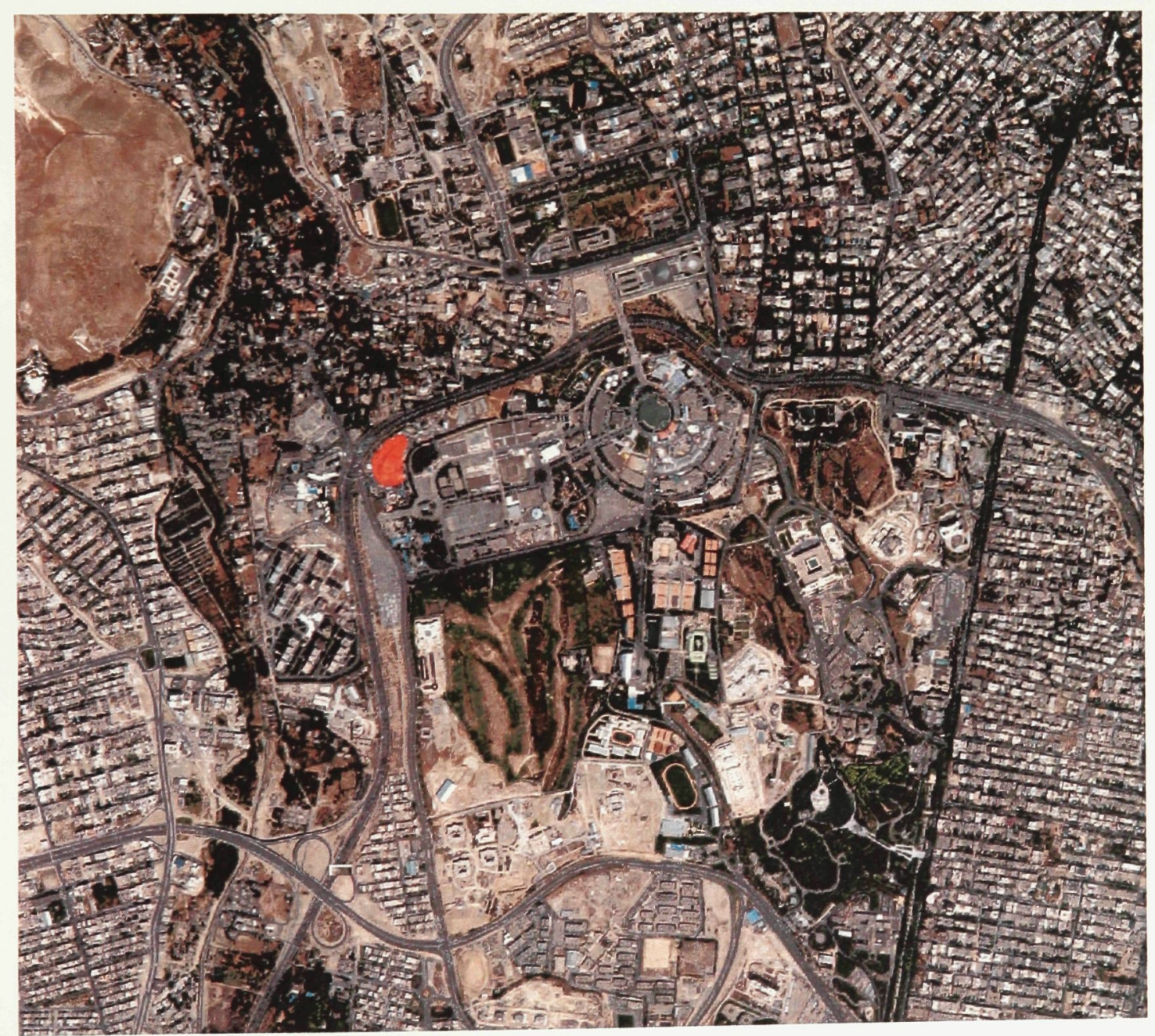

Figure 20 Aerial Photo of the site and neighboring context 
The chosen site for the International Carpet Trade Centre is Tehran's former largest amusement park. The park was named Shahr-e-Bazi (meaning The Game City in English, formerly Luna Park), and is currently owned by the City of Tehran. The selection of this particular site is intending to reflect the idea of heterotopia within the city, as an ideology explored in the previous chapter.

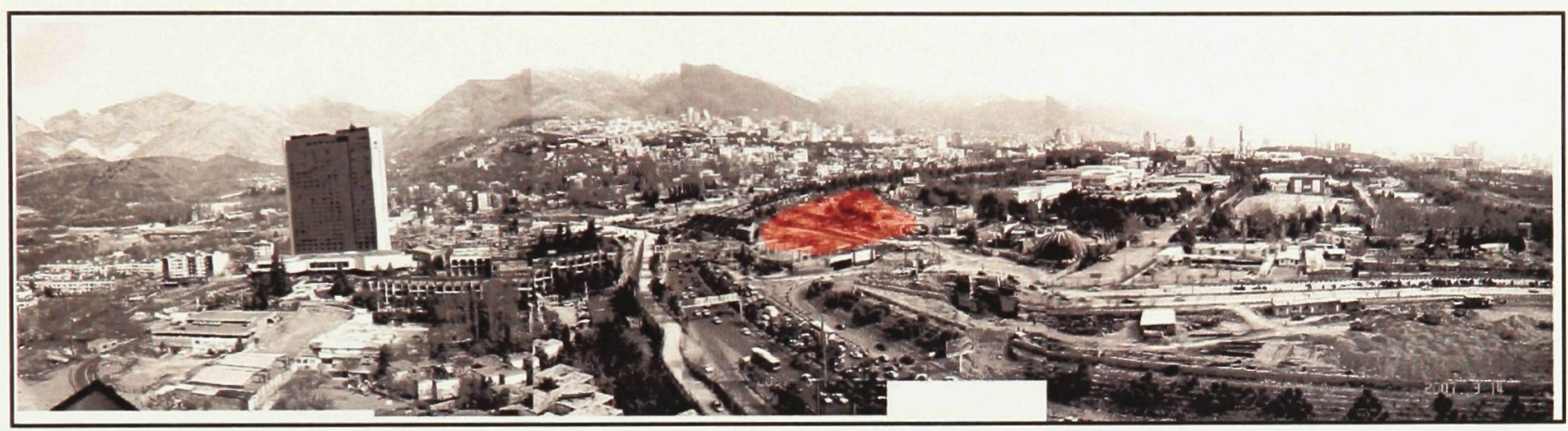

Figure 21 Photomontage of the Site, Tehran, Evin Neighborhood

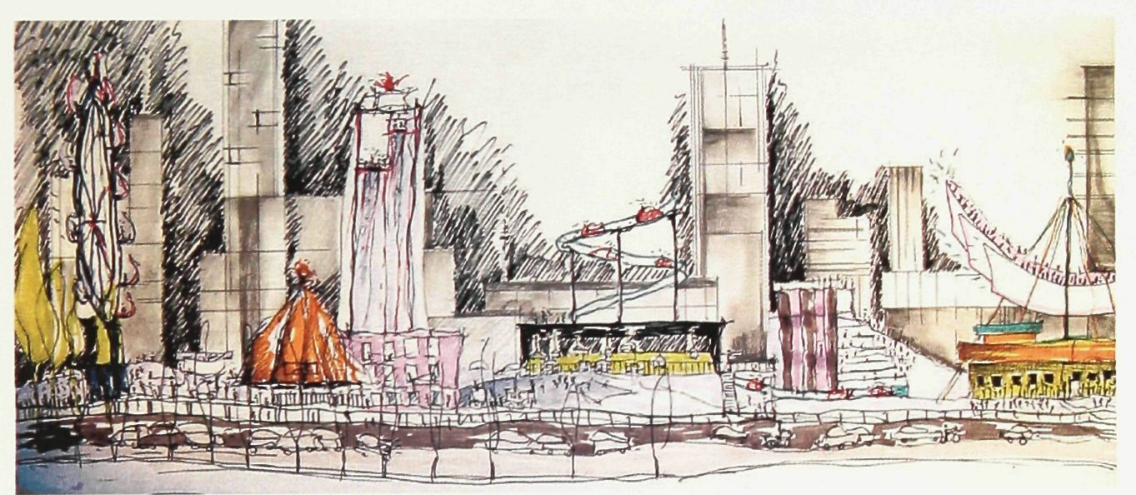

Figure 22 Drawing of the Luna Park Based on my memories. View from the Chamran Highway (west view of the park)

Tehran's former Shahr-e bazi is located in the north of the city in the Evin neighborhood, and adjacent to the Chamran Highway. This highway, divides the Evin 
neighborhoods' residential segment from the institutional/ government segment. The park was built in 1970 during the Shah's Regime, and after the Islamic Revolution, it was taken over by the Iranian government. The park was regularly used by the public, until the City of Tehran decided to move the park to the suburbs of Tehran in November of 2006. Since the architectural program proposes aspects of heterotopia to be reflected, selection of the Luna Park site which had always been a heterotopia within the city of Tehran was appropriate for the design of the thesis project. Once an amusement park, it was suggestive of a leisure place for Tehran's citizens; creating a strange juxtaposition within the institutional/ government and residential buildings.

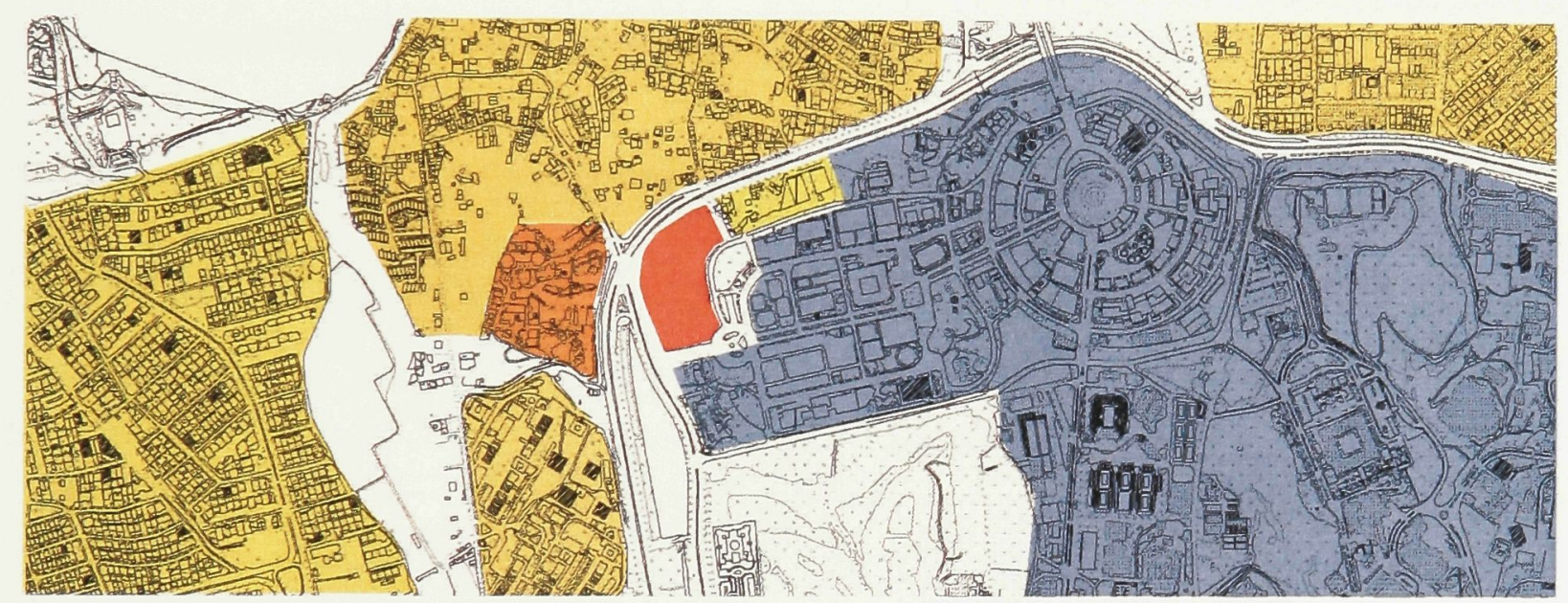

Figure 23 Site plan. Red represents the site, Yellow represents residential, Blue represents public buildings

On the East side of the site, are located a series of institutional and government buildings such as an elementary school, the Ministry of Food Industry offices and the Health Ministry. In addition to that there is a Mosque, and a Sports complex located close to this site. On the west side of the site (the other side of Chamran highway) is primarily a residential neighborhood. In addition to this there is also two of Tehran's major hotels 
located on the west side of the highway. It is this collage of urban and suburban context that makes the Luna Park site a major landmark in the city of Tehran. This array has allowed the potential for creating interesting experiential spaces, creating visual engagements from the proposed building to the existing highway and Evin neighborhood; increasing the possibility of a heterotopic space.

\subsection{Process and Design- Architectural Project}

The theories discussed earlier play a large role in the design of this thesis project. The initial exploration of carpets and textile crafts within earlier Greek and Persian societies formed some of the design principles, including an exploration of heterotopia as one of the main inspirations in the design of the building.

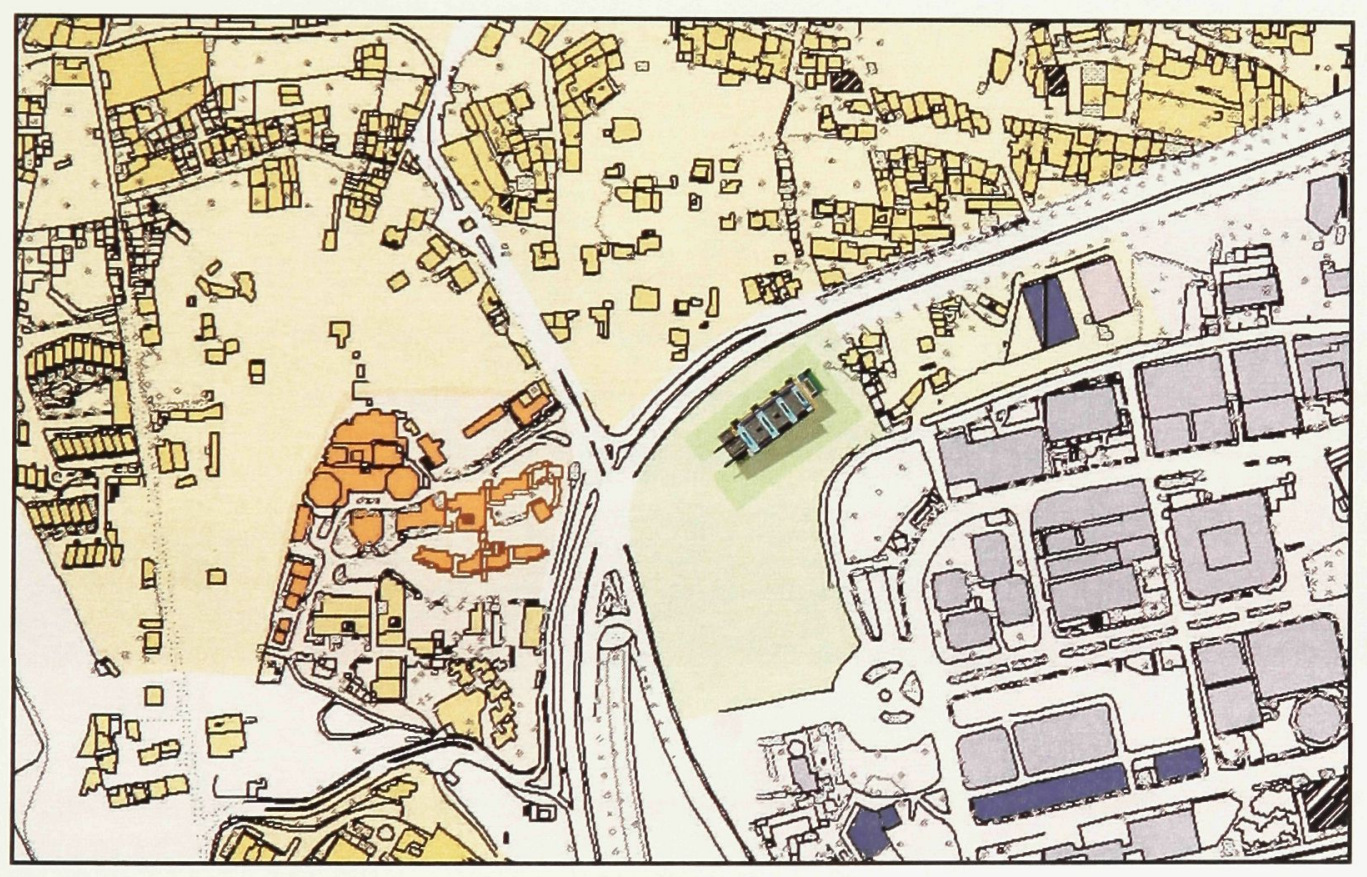

Figure 24 Site Plan

This building is a centre for carpet trade purposes, cultural functions, and exhibition spaces for Tehran's citizens and tourists. The exploration of heterotopia within 
this building is achieved through the specific selection and composition of the developed programs, including the major programmatic space of the building which is the bazaar. Similar to the medallion element within a carpet, this program acts as the heart of the building, as it is located on the fist two levels of the building and all other programs extend out from it. This can be seen in the study of a longitudinal sectional drawing through the building. The second floor of the bazaar is one of the main spaces within the building that has a clear view to the highway and cityscape.

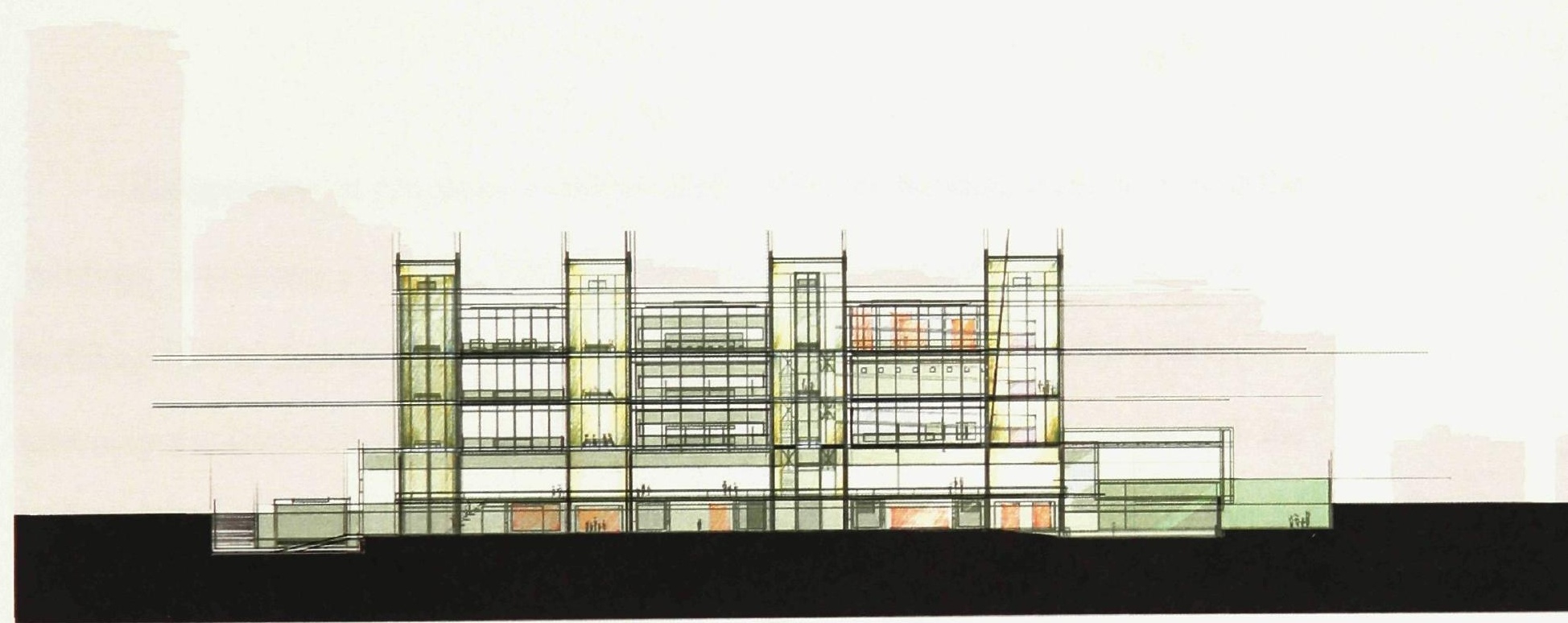

Cross section- 1

Figure 25 Sectional Drawing, showing the relationship of the bazaar (first two levels of the building) with the rest of the Programs

Having the coloring exhibition (another major program) on the same level as the bazaar space creates an interesting juxtaposition within this space for the viewer. The two 
programs in dialog together, reveals to us the implication of time in the making of these carpets; including its coloring and weaving. As discussed, Foucault also introduced this idea within heterotopias as "slices in time". Therefore through the type of the programs, this building create slices in time; breaks the viewer's conventional time and connects him to different times in different spaces. The lower space of the bazaar is where the exhibition of the carpets is to happen; a deliberate strategy to protect the carpets from excess lighting. The carpets are displayed on the walls or hung from the structure, and there would be no direct sun light on them. The bazaar is also heterotopic because of the juxtaposition it creates externally, through its relationship to the existing context, which as discussed includes the government and the residential community.

Juxtaposition of programs is also created within the building itself as well as the buildings' surrounding context. The cityscape and the view to the highway, act as a backdrop visible through various openings within the bazaar space. In other words heterotopia is achieved through the juxtaposition and relationship of the bazaar with the urban context of the city; mimicking the idea of the juxtaposition between the carpet and its physical surrounding. The bazaar space is in fact the very public part of the building, and it is the first space the viewer experiences after passing through the threshold of the entrance. 


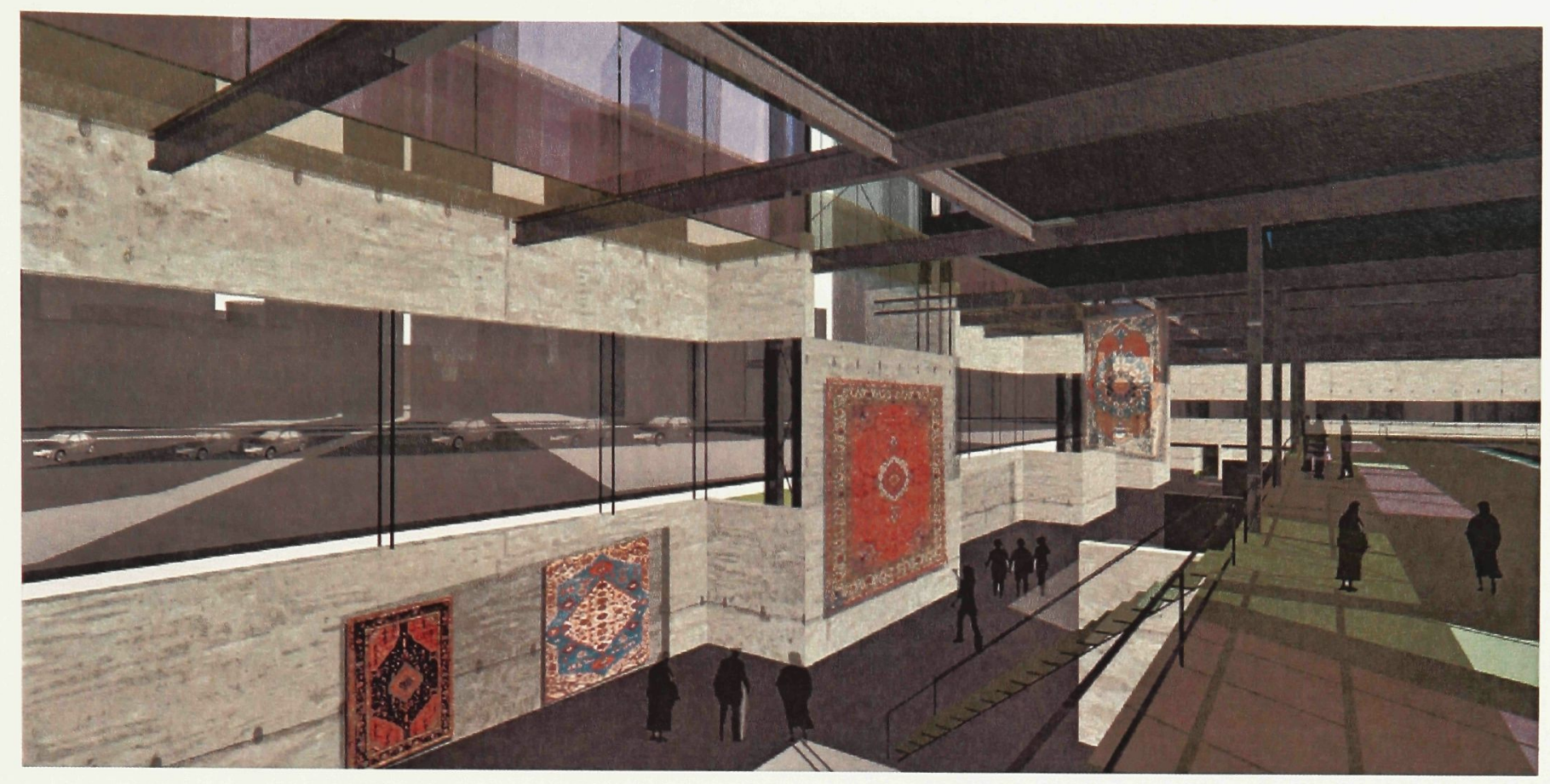

Figure 26 Interior of the Bazaar space. Showing bazaar space with the cityscape as a backdrop

Other significant programs that reiterate heterotopia within this building include the exhibition space/gallery for buyers, as well as the exhibition space of carpet weavers. The space to exhibit carpet weavers brings the performance of a weaver on her loom and carpet observable for the public. As mentioned earlier, weaving is done within the tribes in the outskirts of the cities in Iran. Therefore, an exhibition space dedicated to them within this building creates an interesting relationship between the weavers and the City itself; enforcing the idea of heterotopia. Within these exhibition spaces there are a series of openings that create a visual engagement to the surrounding context. By visually engaging the viewer to her/his surroundings internally, and externally, one can experience the notion of heterotopia. "The heterotopia is capable of juxtaposing in a single real place several spaces, several sites that are in themselves incompatible."97

\footnotetext{
${ }^{97}$ Michel Foucault Of Other Spaces, Heterotopias, Architecture Movement October, 1984, p 4
} 
Other Programs within this building include administrative spaces, a small school to teach weaving and carpet designing, a bookstore, a tearoom, a theater space for cultural purposes and a coloring/dying exhibition.

The building is divided into four main programmatic sections with circulation spaces running in between each of these sections. The bazaar space is the feature space located on the first two floors, with the three other divisions (three story tower like volumes) extending up from it; creating three more stories above the bazaar space. As mentioned, the three are connected through the circulation, making it a convening space for the public. Small gardens integrated within these spaces, also makes them more significant as public gathering spaces.

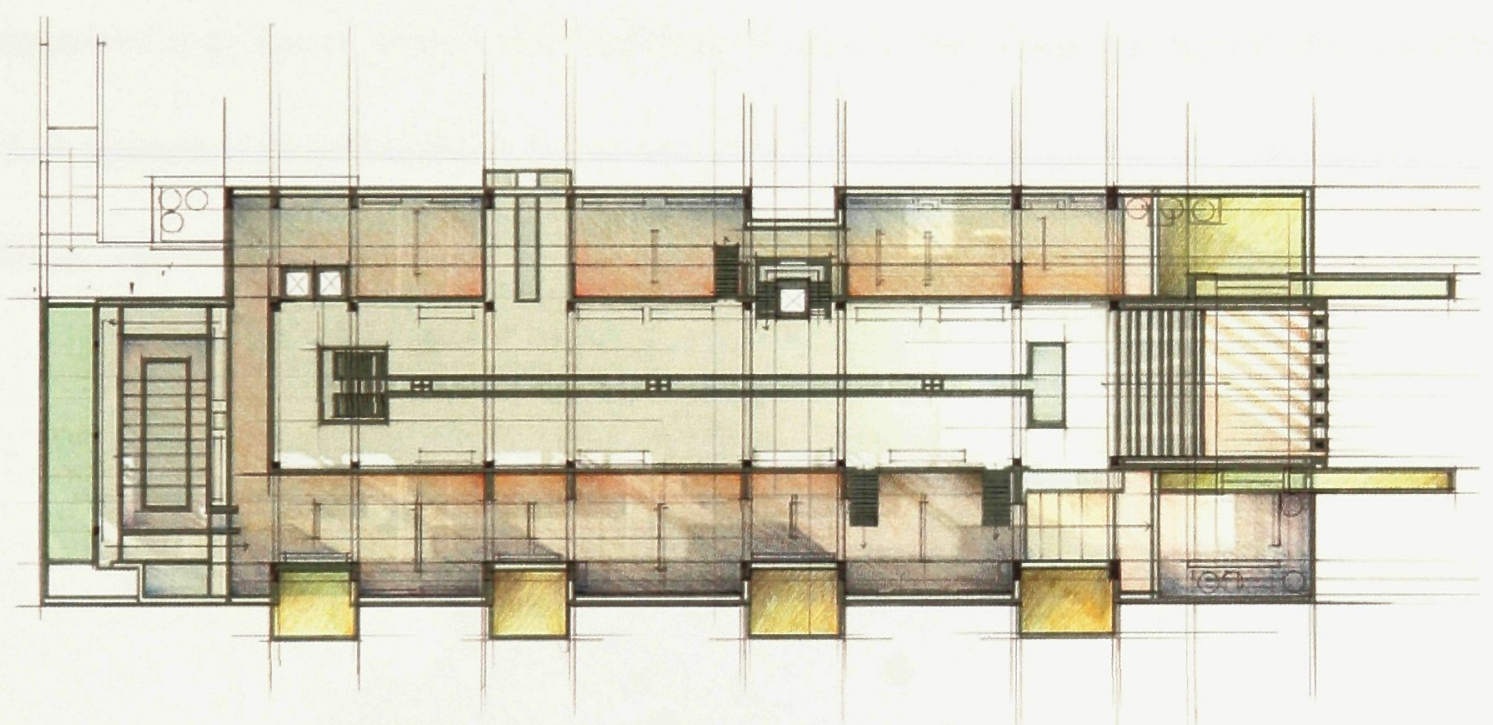

Figure 27 First Floor Plan. Showing the bazaar space, the water feature in the middle, the entrance on the right side, as well as the dying coloring exhibition and its juxtaposition with the bazaar space.

Another inspiration for the design of the building came from the idea of a loom; however it was not the main focus of the design project. Structural elements are mainly 
used as an exposed design features particularly on the west and east façades. This is to metaphorically convey Greek thoughts on the structure of a loom and its relationship to the carpet. As mentioned by McEwen, the very idea of the post and beam looms was brought into Greece from Persian culture in the pre classical time. As discussed in chapter two, the Greeks understood the structure of the loom as a means for brining the carpet into the cosmos, and making them appear. The structural strategy in the design of this building attempts to convey the very same idea. The west and east façades are held by vertical structural elements that are visible from the exterior of the building. Certain parts of the structure are exposed, showing how the surfaces such as the façade or floor plates are either resting on the structure or being supported by it. This further conveys the relationship of the loom to the carpet as a surface. Ultimately the structure becomes an organizer of the spaces within this building. As the loom holds the carpet and is a means for it to appear, metaphorically, the structure of the carpet trade centre makes this building "appear".

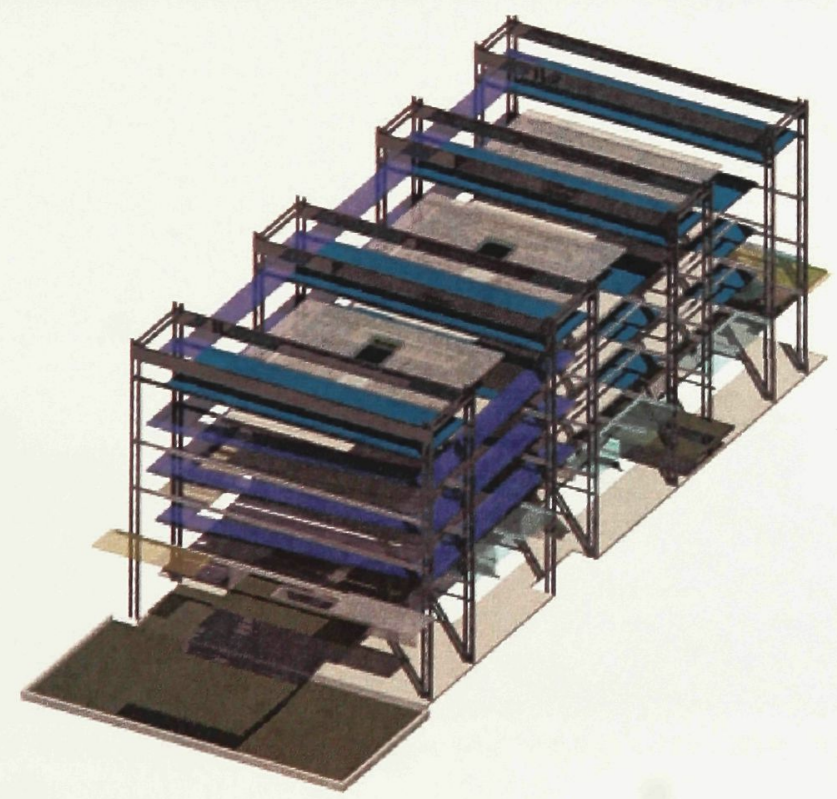

Figure 28 Axonometric Drawing, Overall Structure of the Building, Inspired by The structure of the loom. 
The next design strategy is a reflection of the boarder element as metaphor for the development of the facades in the architecture of the thesis project. As discussed previously, the images of boarders around Persian carpets are representations of the four walls around the garden carpets or gardens, making these spaces sacred and significant. In the design of the Carpet Trade Centre, the double wall system is used to convey the similar idea. The first layer of the façade is a composition of transparent and translucent glass, however there is another layer of translucent walls (with strategically located openings on them) wrapping programmed spaces within the building. Exploring materiality on the façade also helped to achieve this idea. Looking from the exterior of the building, the movement of people can only be observed within the circulation spaces placed in between these two walls. Some of the main interior of the building are strategically placed behind the second layer of the walls, in an attempt to be elusive from the exterior. The placement of the circulation adjacent to the facade allows the facade to become very animated, creating a playful visual engagement in relation to the existing highway.

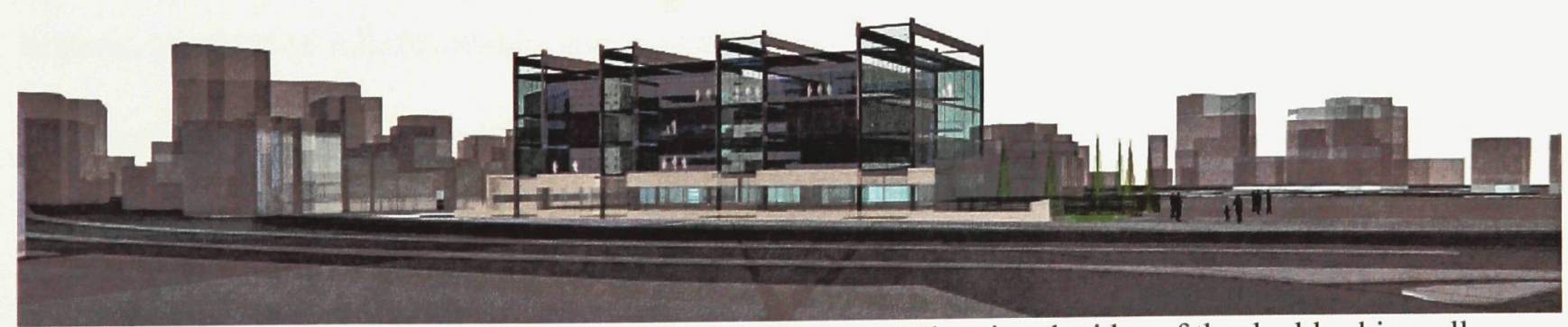

Figure 29 Exterior view of the west Elevation and the highway. Showing the idea of the double skin wall and animated facade. 
Other key architectural elements brought into the design that is based on the studies of carpets are such as a water feature, and small internal gardens. In other words nature is pulled into the building; constantly reminding the viewer the idea of the carpet as a representation of the garden in the interior spaces. The carpets are to represent an illustration of the nature in architectural spaces. The water feature is located in the vestibule space of the bazaar, close to the entrance, and acts as the initial public gathering or meeting place of the building. It runs through the vestibule, dividing the bazaar into two; bazaar for residential and a bazaar for commercial carpets.

Next architectural features are the small garden spaces, located on the roof top of the bazaar on the east and west façade. The gardens are located in between two programmatic spaces and are designed so that one can have a visual engagement to the two spaces while physically located within the internal gardens. For instance while experiencing the gardens on top of the bazaar; there is a heterotopic engagement between the bazaar, the gardens and the view to the city

According to Foucault's Fourth Principle, heterotopia is introduced as a "series of opening and closing systems, which makes these spaces either isolated or penetrable" $" 98$. Therefore the entrance to the Carpet Trade Centre becomes significant. As Foucault argues, to enter to a heterotopic space one should make a "certain gesture". The attempt is to celebrate the entrance space through the use of reflective materials, and use of steps. Elevating the building higher than the ground can be suggesting the effort the viewer is invited to make in order to pass through the threshold.

\footnotetext{
${ }^{98}$ Michel Foucault Of Other Spaces, Heterotopias, Architecture Movement October, 1984, p
} 


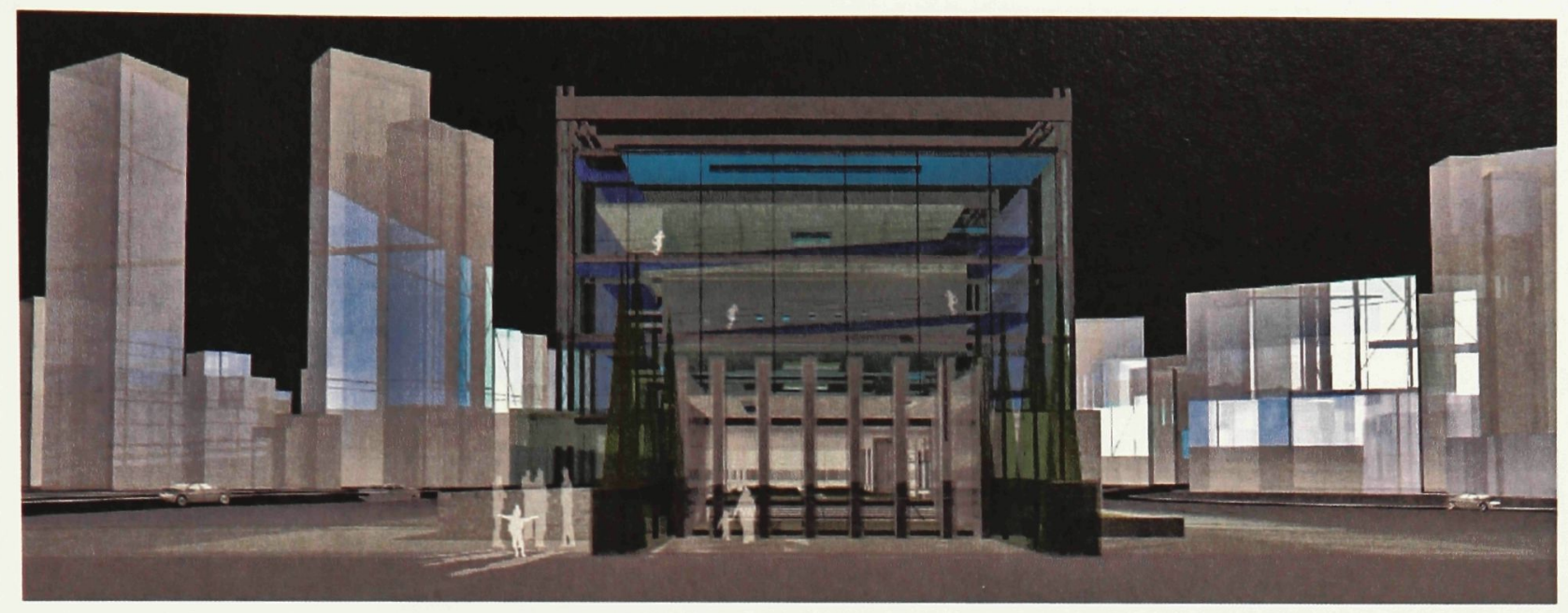

Figure 30, Front elevation (south elevation), showing the entrance space and the facade

The design of this building explores the idea of heterotopia through the selection and composition of the program, and the key architectural features as they were inspired by the study of carpets within the two civilizations. Inspiration from the Greek ideologies on carpets, such as the structure of the loom, is implemented in the structural aspect of the design. On the other hand architectural elements such as the division of the main programs into four, the water feature, the voids within the building, and the gardens were inspired through the study of Persians' thoughts on carpets. Ultimately, by analyzing the Persian carpet as a heterotopia, many design strategies were informed. Some of them discussed in this chapter were such as creating juxtaposition within the building as well as with its context, celebrating the entrance to the building, and exploring a double façade condition. 


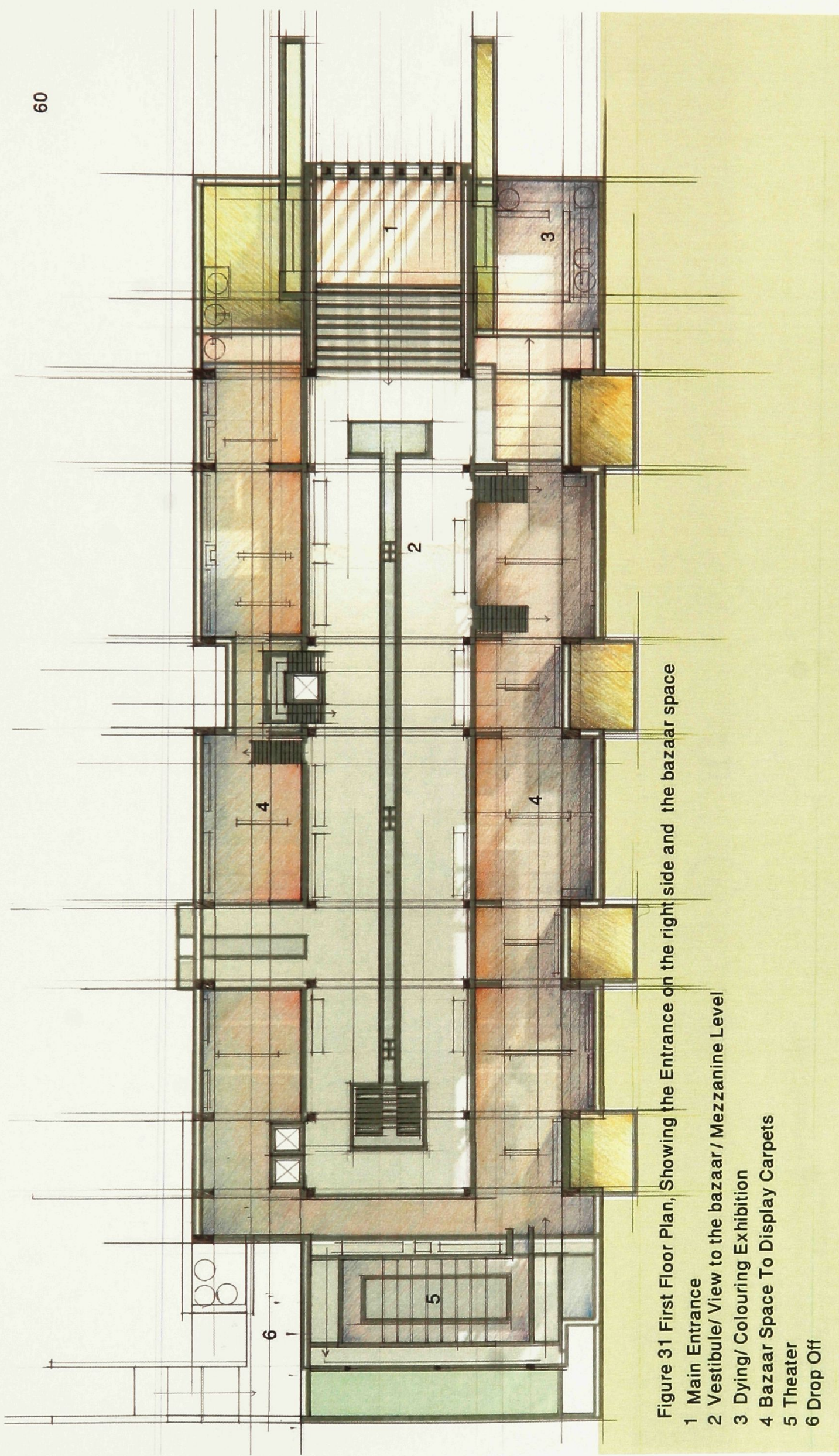




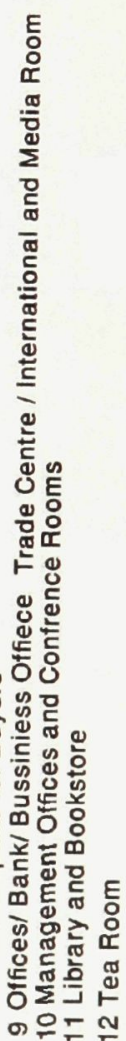



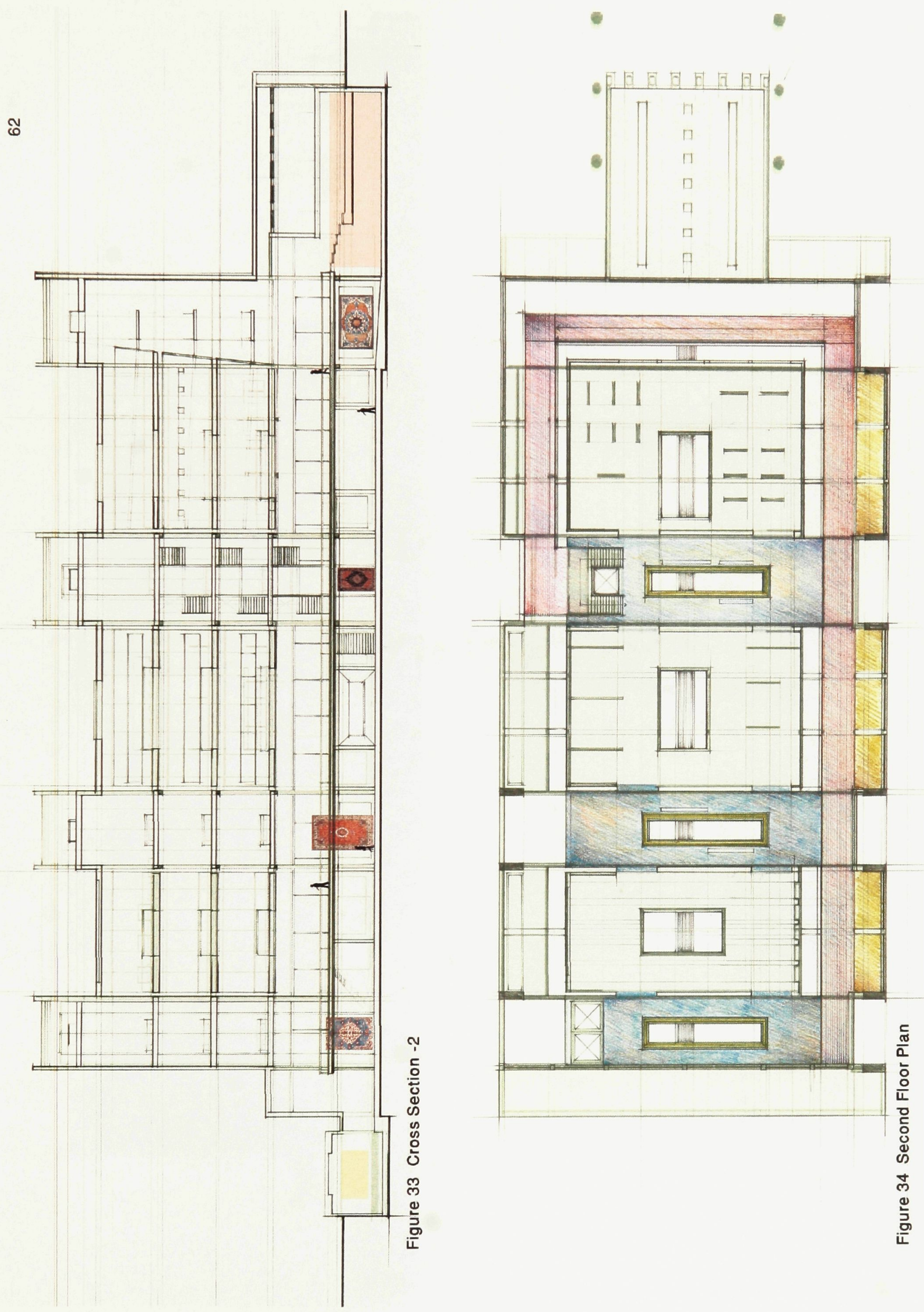


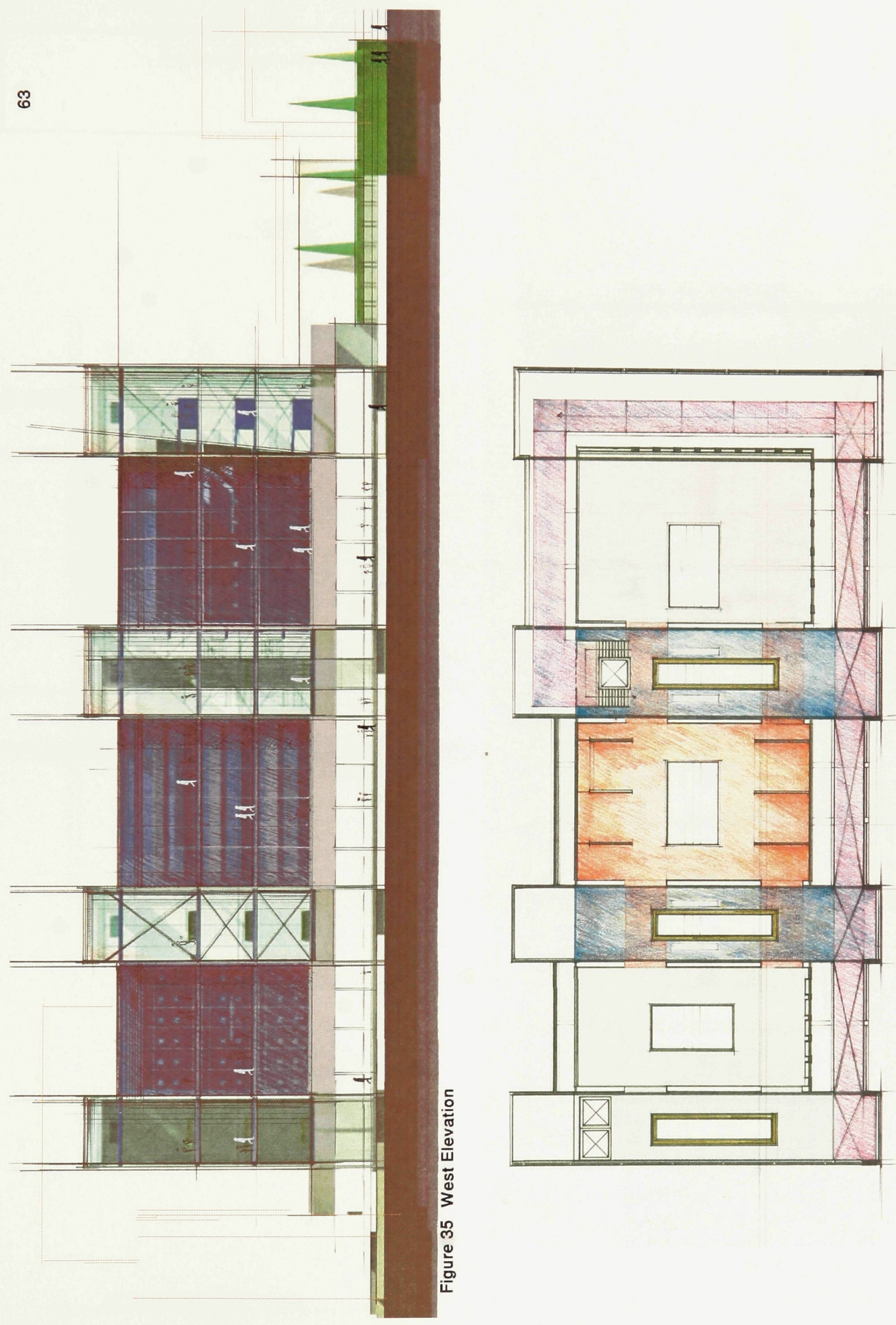

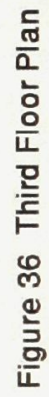




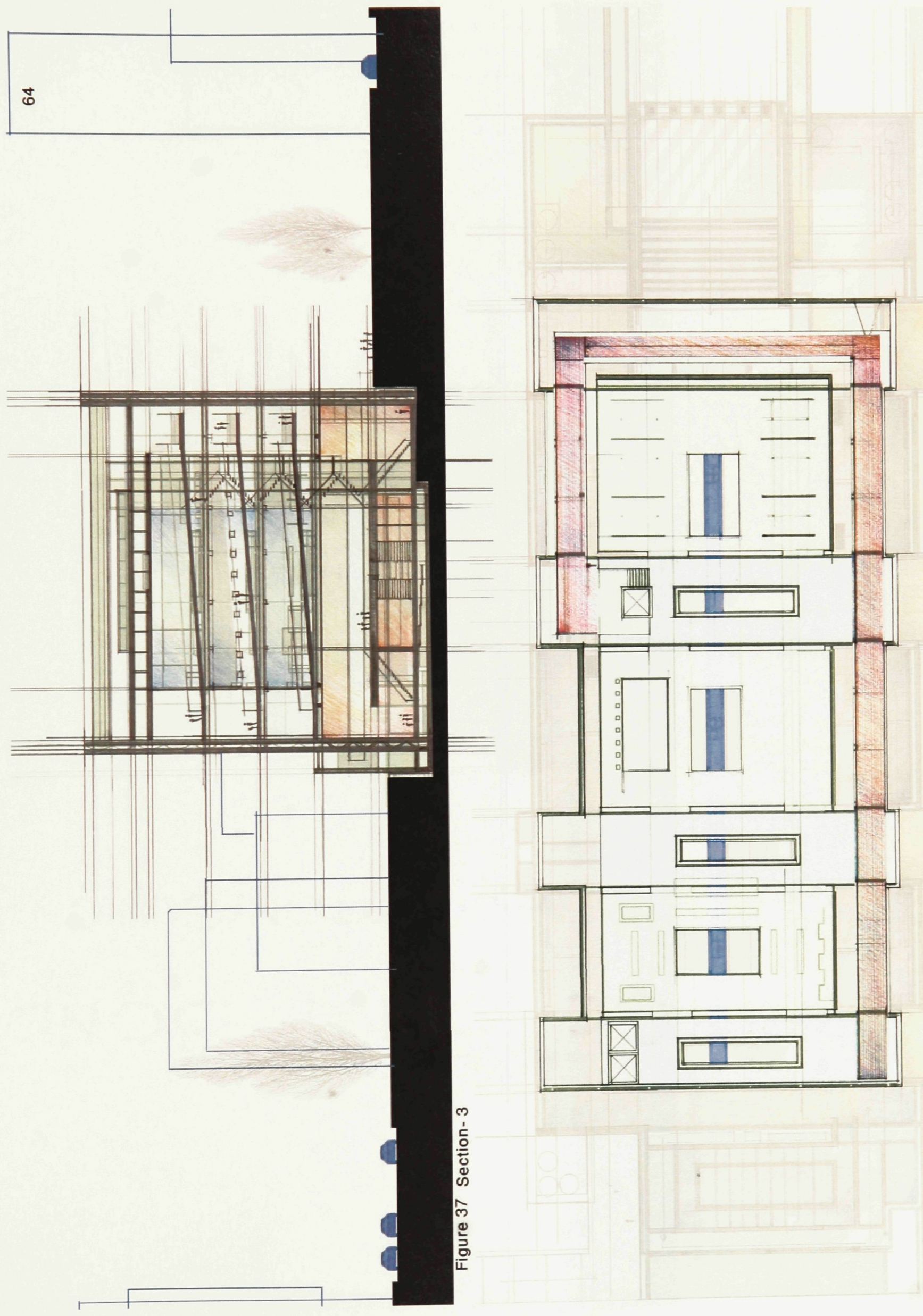

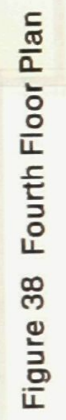



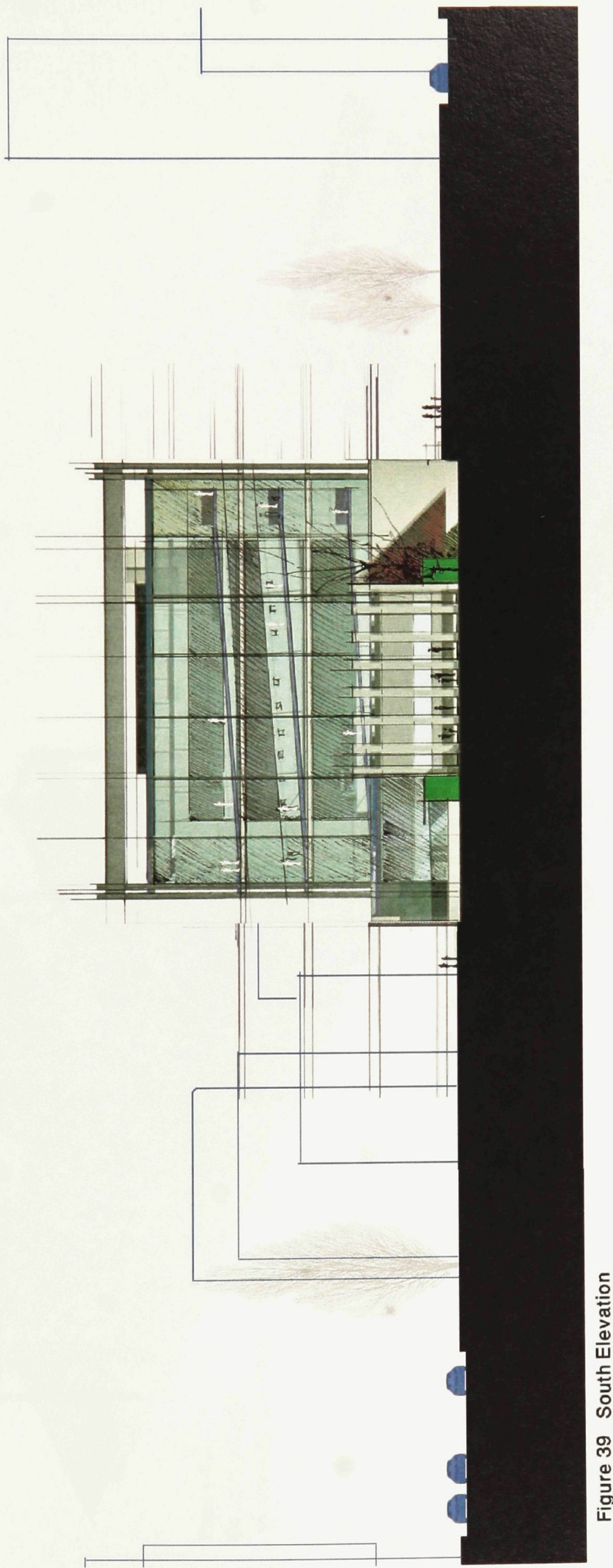


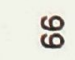
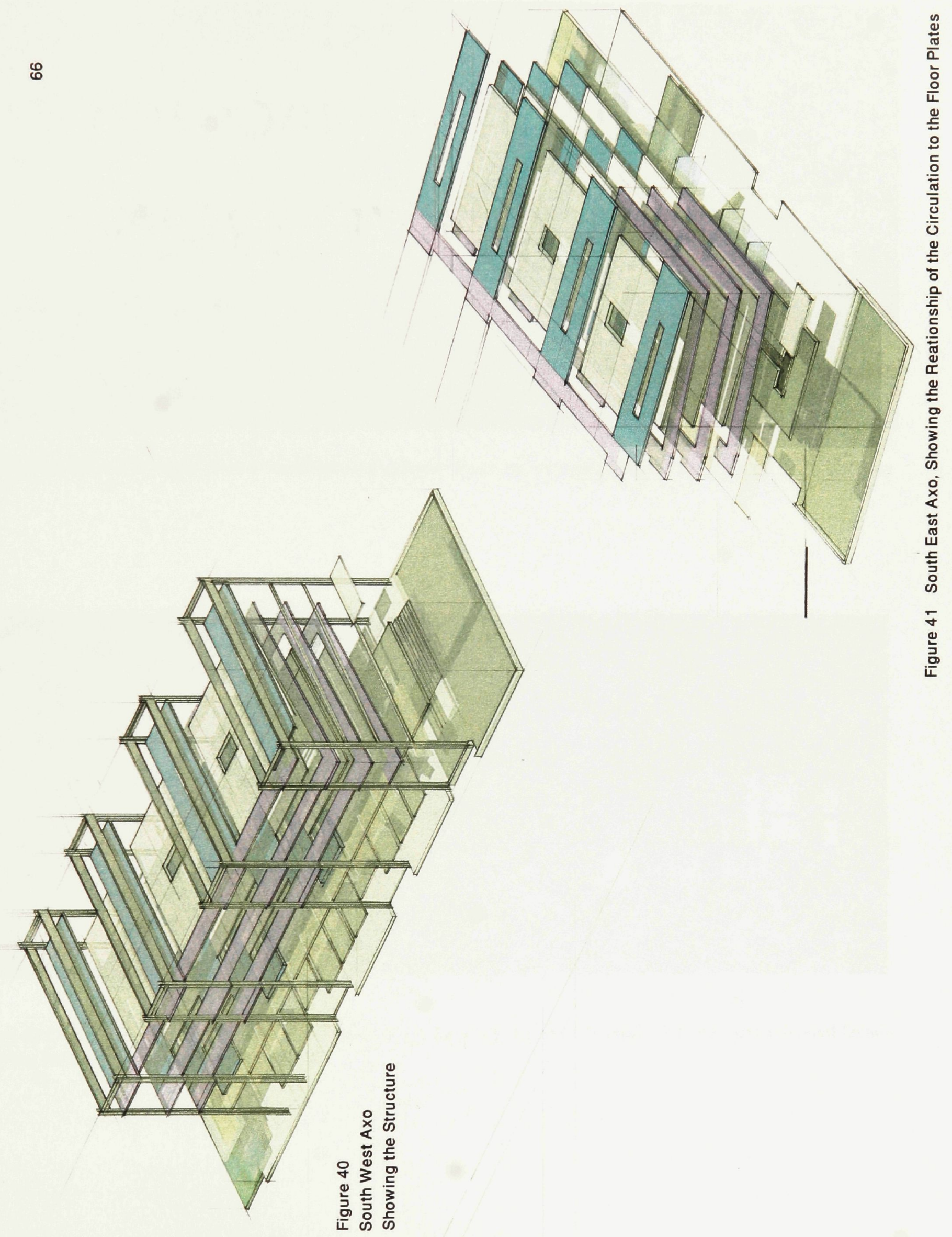


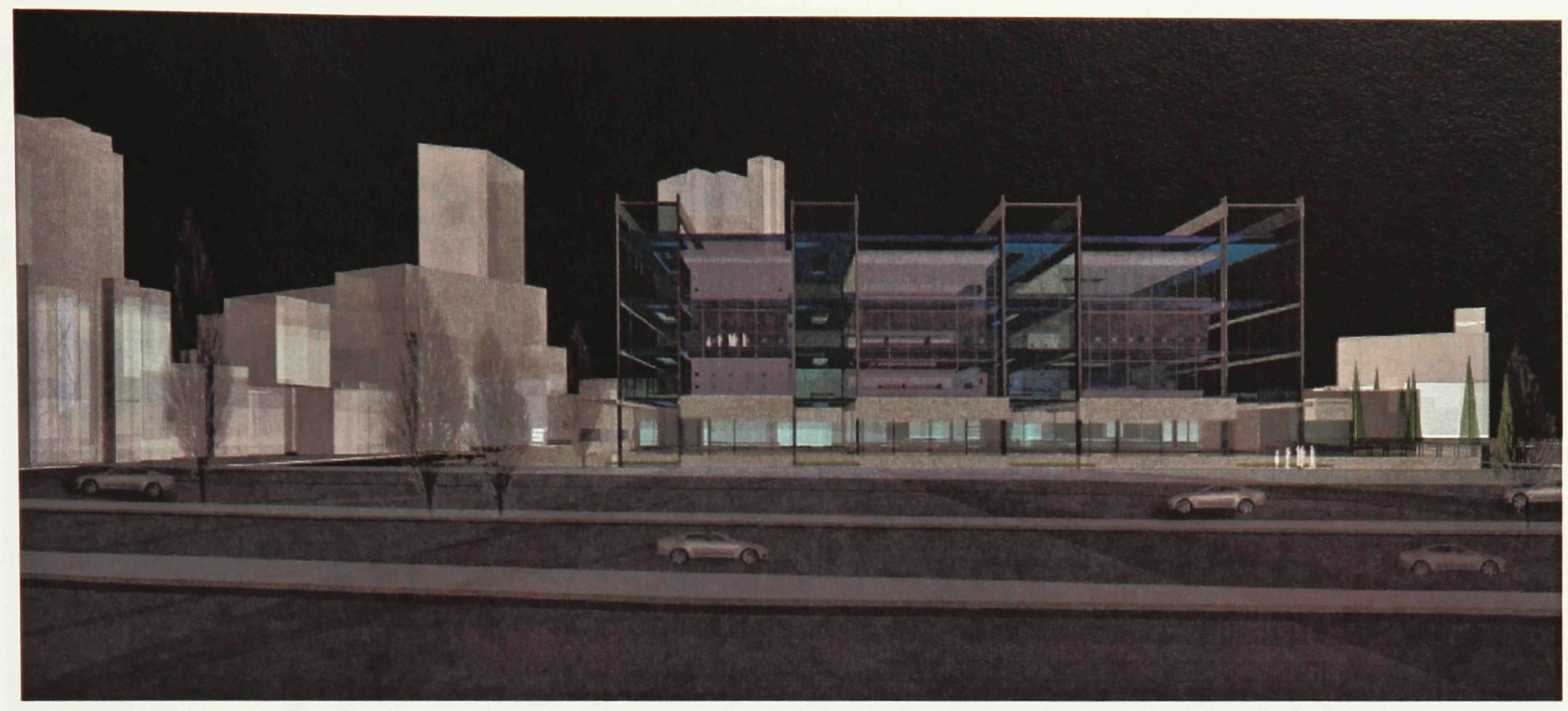

Figure 42 West Elevation- night view from Chamran Highway- Showing the relationship of the building to the highway

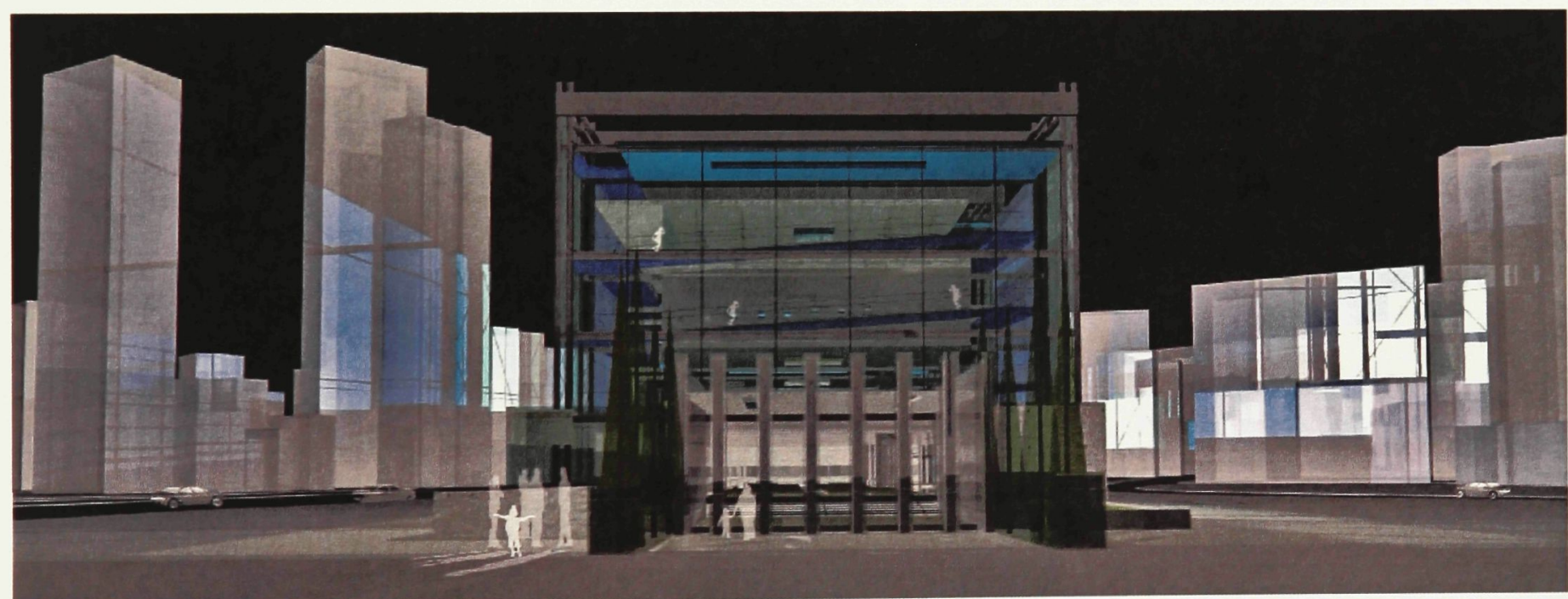

Figure 43 Exterior front view of the building. Night view. Showing the idea of double skin wall and animated facade Showing the celebrated space of the entrance 


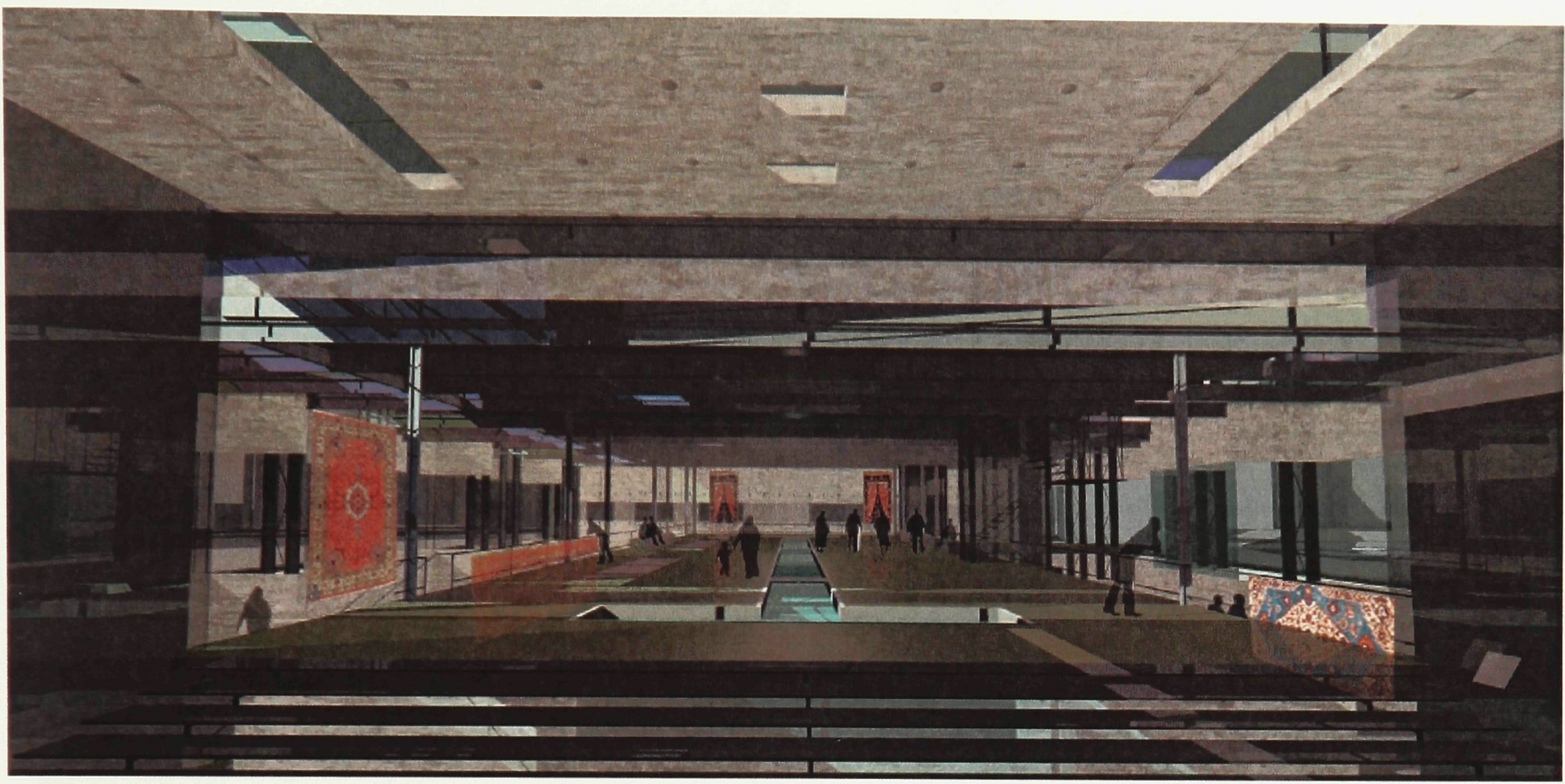

Figure 44 Interior View of the Bazaar space from the entrance. View to the Vestibule and the water feature

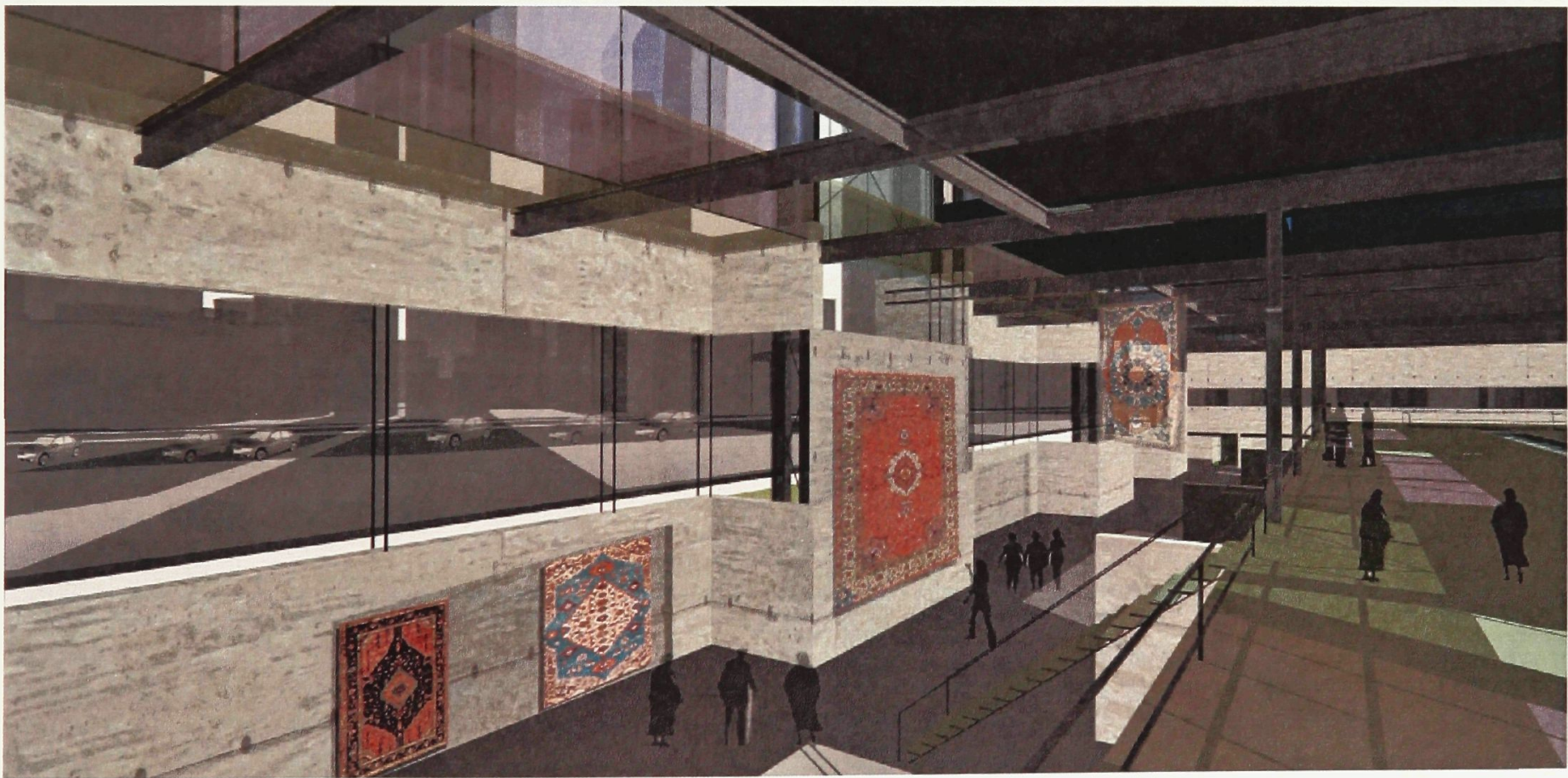

Figure 45 Interior of the bazaar and the vestibule area. Juxtaposition of the Bazaar to the highway and cityscape. Exposed structure, used to display carpets 


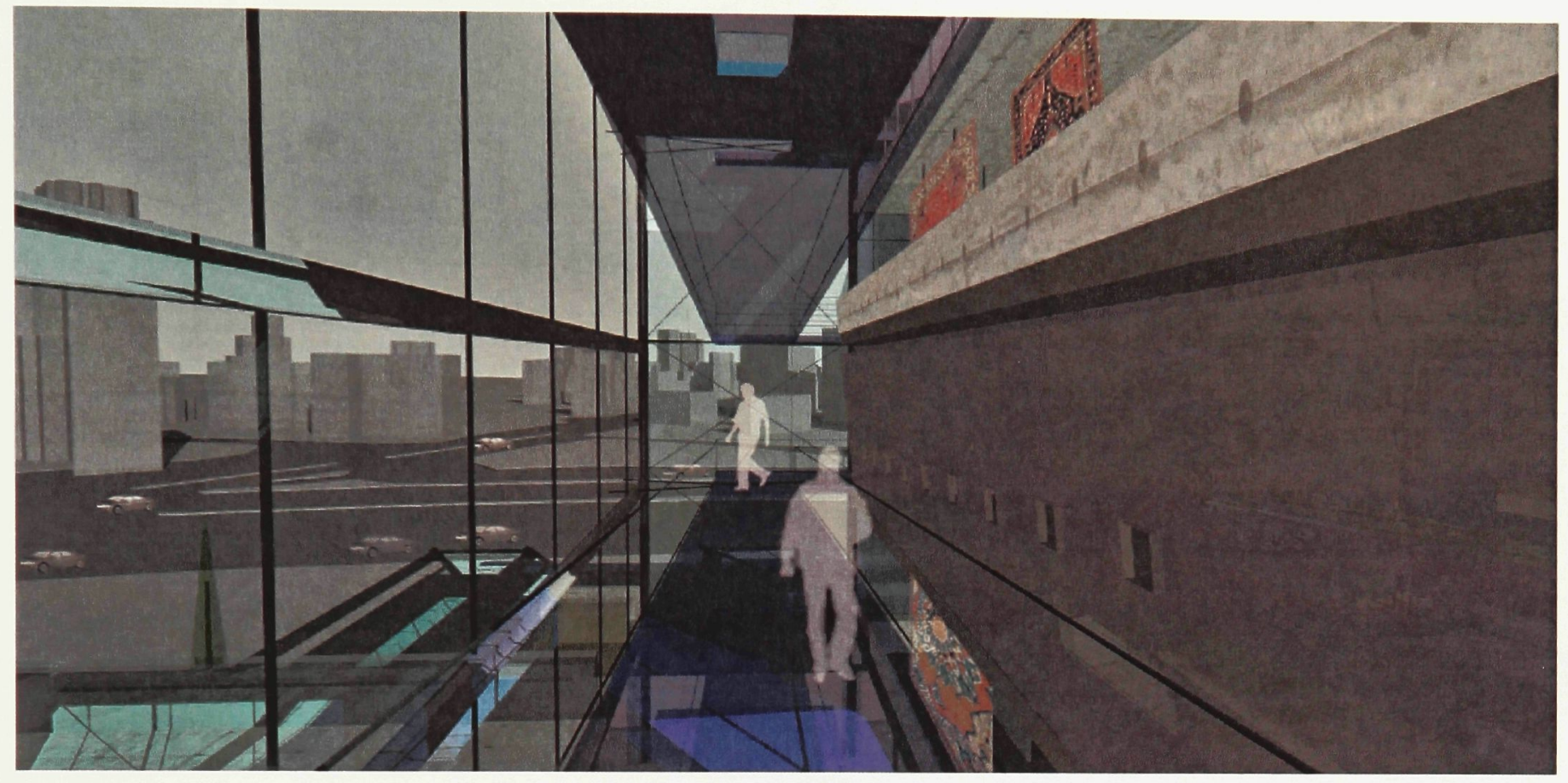

Figure 46 Interior view, showing the ramp next to the exhibition space and the school area along with the view to the surroundings through the glass curtain wall 


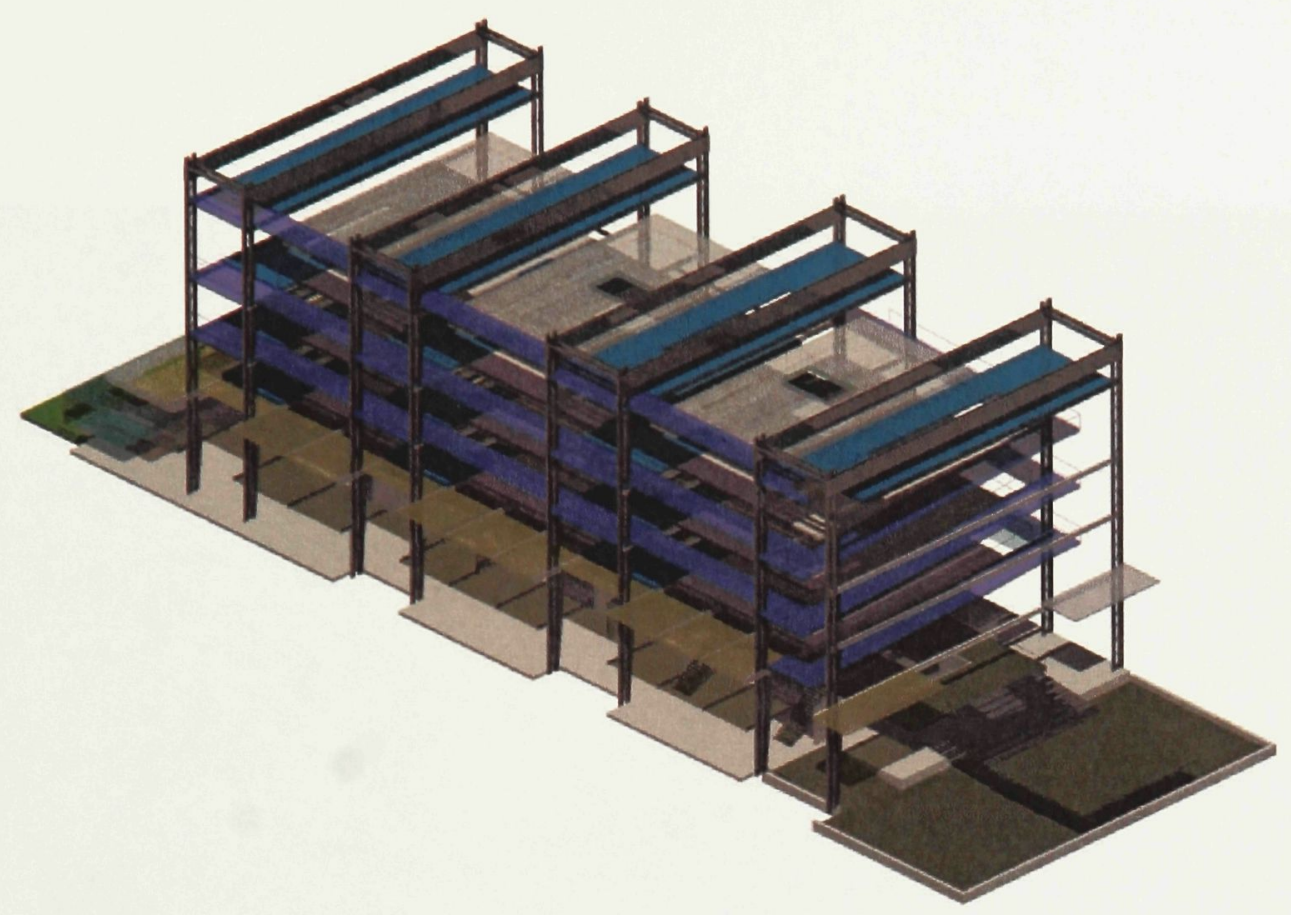

Figure 47 Axonometric View of the overall structure and floor plates. Showing the relationship of the circulation space( illustrated in purple) to the floor plates . showing the relationship of the structure to the floor plates.

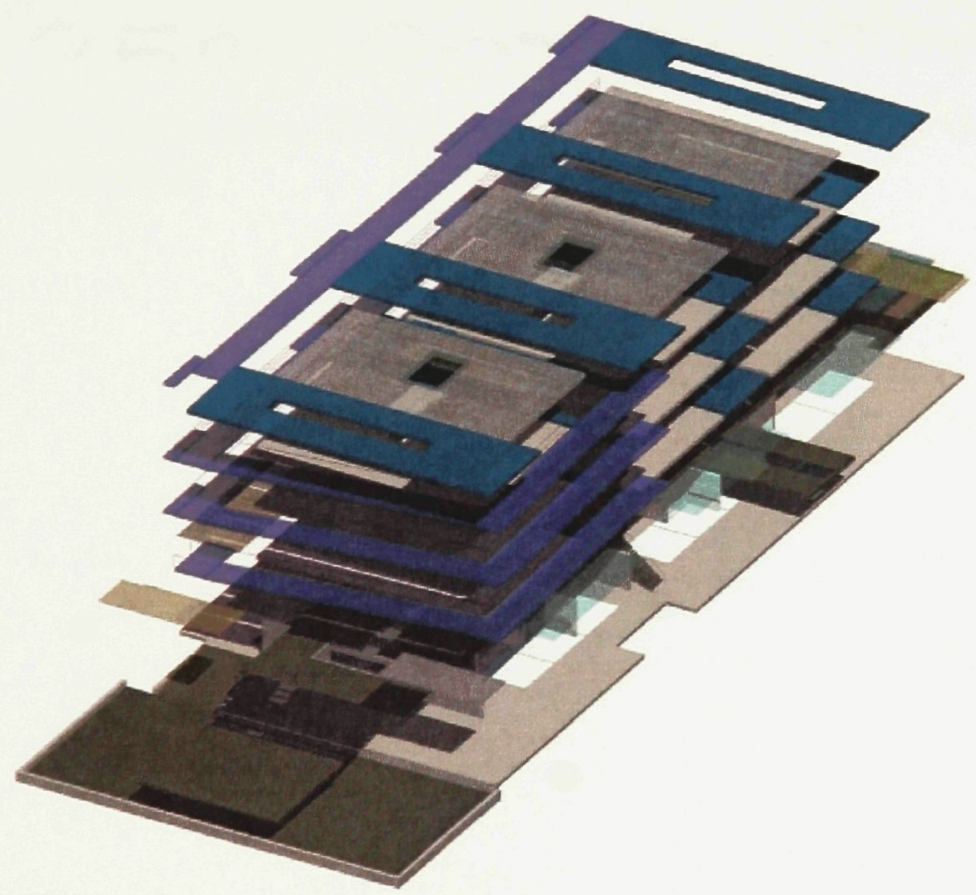

Figure 48 Axonometric view 2 -Showing the floor plates and circulation. South east side of the building. 


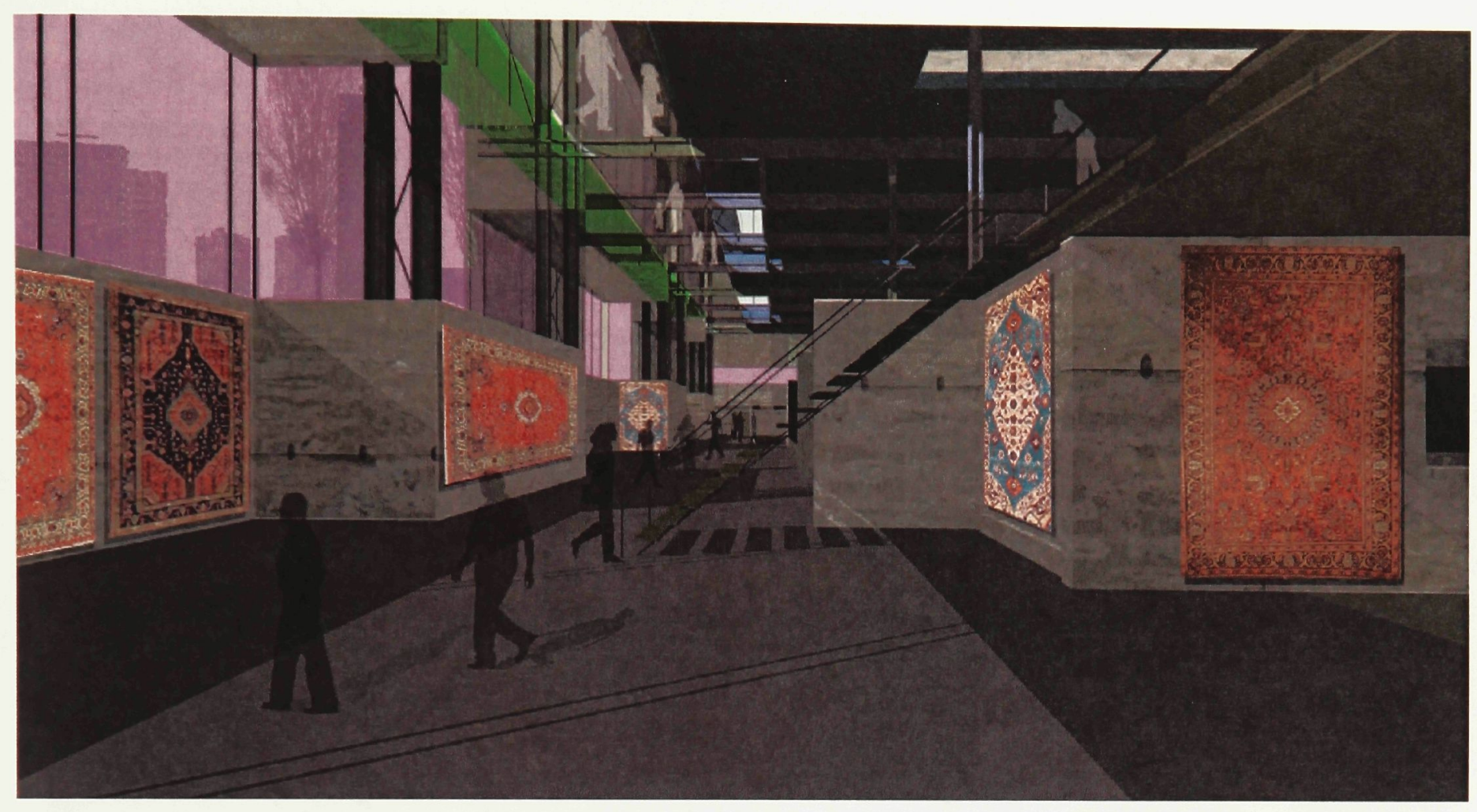

Figure 49 Interior view of the Bazaar space. Showing the juxtaposition of the bazaar with the gardens on top and the view to the city through the openings. 


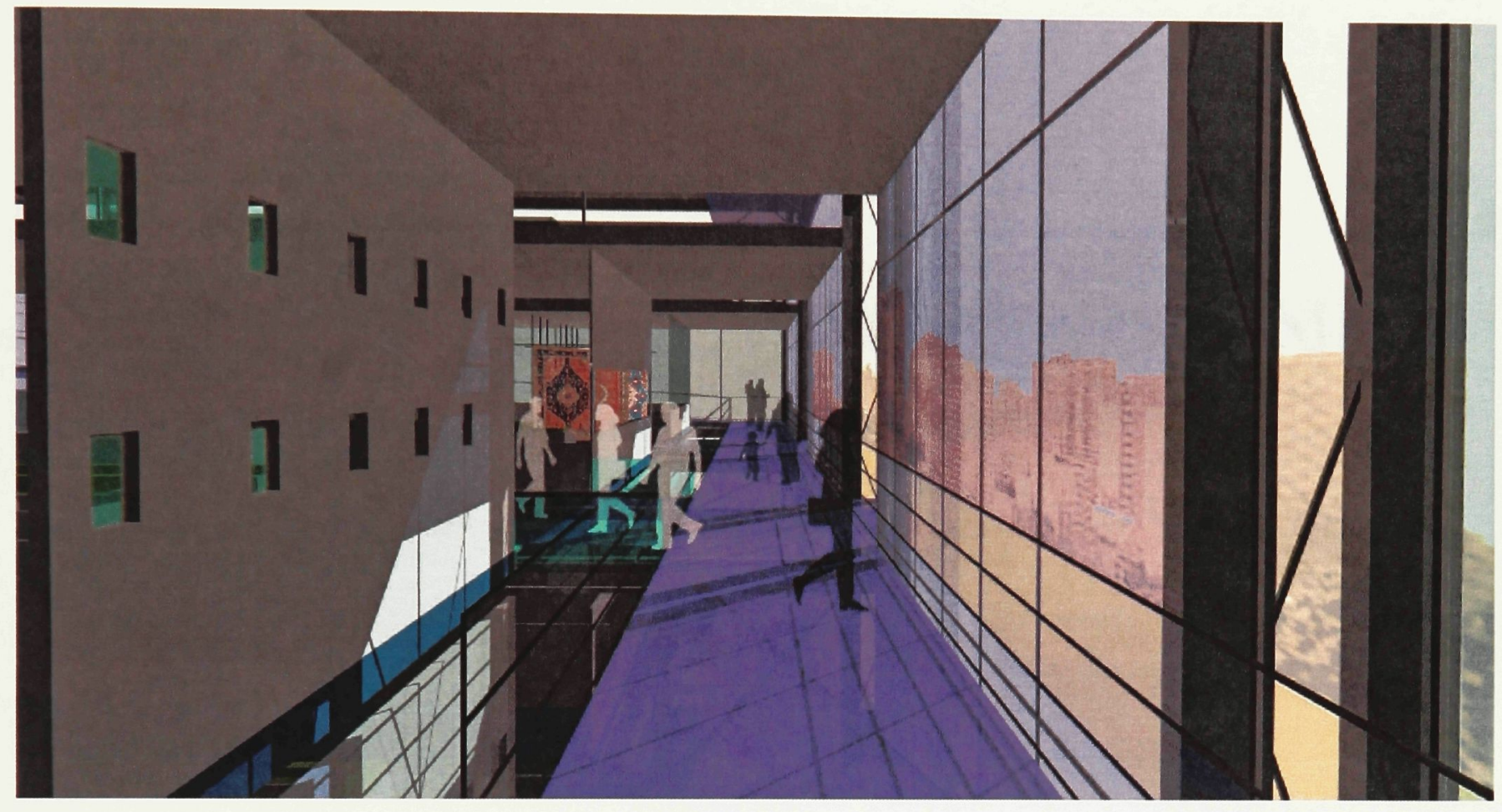

Figure 50 Interior view of the circulation space attached to the facade. 


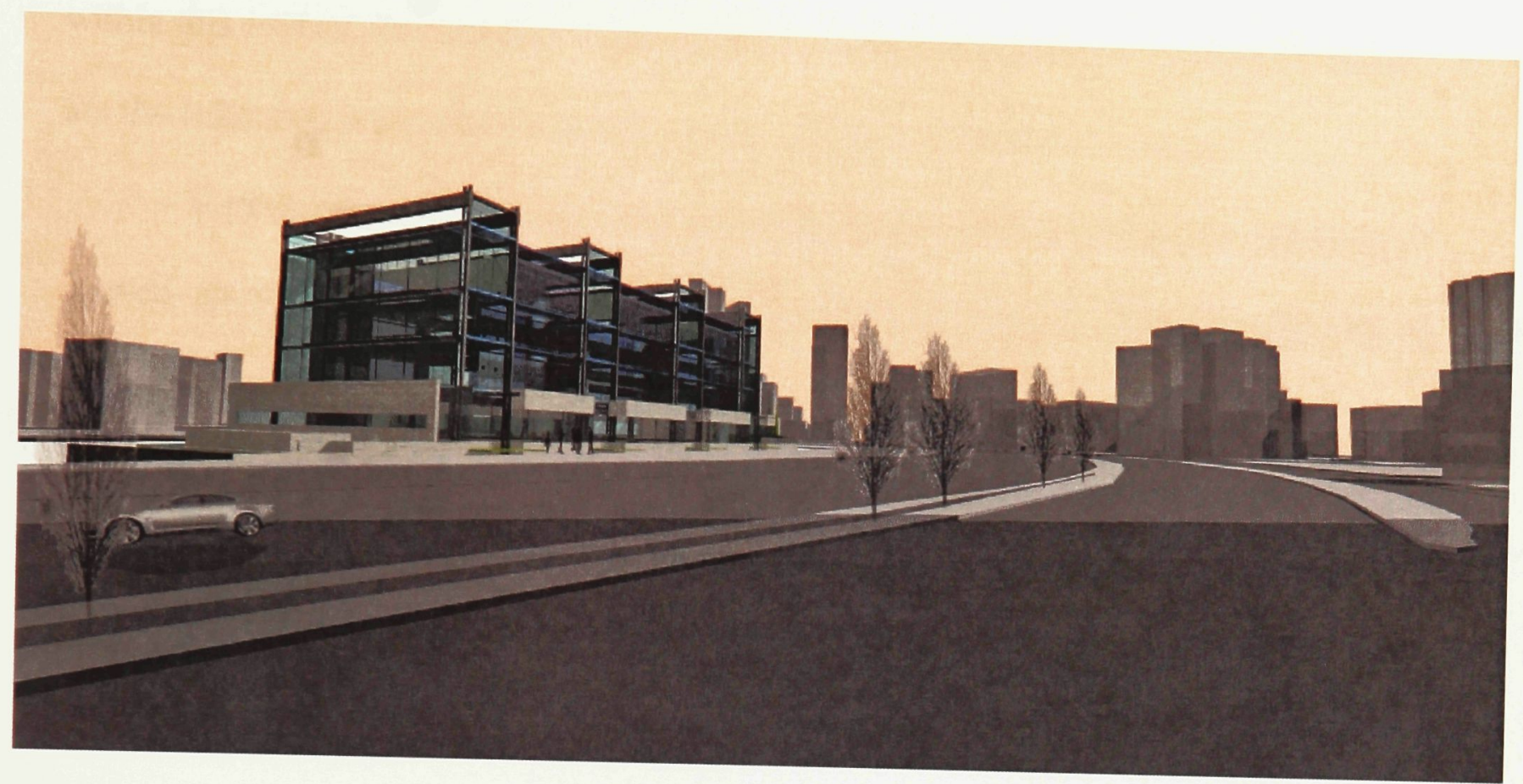

Figure 51 Exterior view of the north and west elevation from Chamran Highway 


\section{Conclusion:}

"The carpet as an earthly garden functions both as an object of man's contemplation, and it is different from a natural landscape in the sense that is abstracted within this artifact. For Iranians the design and fundamental elements of within a carpet are the reflecting principles of cosmic, order, and their definition of beauty." 99

Carpets were always perceived as a manifestation of a garden and a reflection of heaven- spiritual realm- on the earthly world in the Persian culture. Therefore the idea of the garden as an expressive artistic form of art has always been related to Iranian philosophy and worldview. Similarly Greek ideologies also play a key role in the weaving of carpets and other crafts. These two civilizations understood weaving in very different ways due to different worldviews towards the notions of craft. For the two their craft was an illustration and understanding of the cosmos. However, the Greeks manifested that through the very notion of making harmonious craft and bringing it into light, while the Persians manifested the cosmos through colourful imagery and directly illustrated them within their carpets.

The thesis ultimately analyzes the carpets as heterotopic spaces, based on the western idea of heterotopia as discussed by Michel Foucault. Therefore, the experience of the carpet or garden is not limited to the corporeal world, but to some extent makes the reality of the imaginal world and its experience perceivable. Within this investigation, the tradition of the Persian carpet acted as a metaphorical cultural expression that informed the proposal of the International Persian Carpet Trade Centre in Tehran. This was done through the selection and juxtaposition of the programs as well as introducing

${ }^{99}$ Meisami, J, Scot, Allegorical Gardens in Persian Poetic Tradition, International Journal of Middle East Studies. Vol 17 . No 2, 1985, p 5 
architectural elements such as use of different materials, water feature, internal gardens, creating voids within the building to maximize the visual engagement of one space to another, as well as the selection of the site.

This thesis ultimately raises the question about the transformation of heterotopia from a garden carpet to the architectural development of the thesis. Heterotopia as defined earlier is mainly discussed and understood within carpets and gardens; however when it is brought into the architectural space one can question the truthfulness of this term.

In this investigation, some main criteria of heterotopic space was understood within carpets and transformed into architecture. By using architectural design elements such as exploring the entrance space, bringing in the nature into the building as well as creating juxtaposition internally with the programs in the building and externally with the carpet trade center's context, heterotopia was explored.

Therefore now, heterotopia within the architectural space should be studied in relation to experiential qualities of the created space and not to the heterotopic criterions introduced within a carpet or a garden. The building itself, could act as a heterotopia within the context of the city of Tehran. 


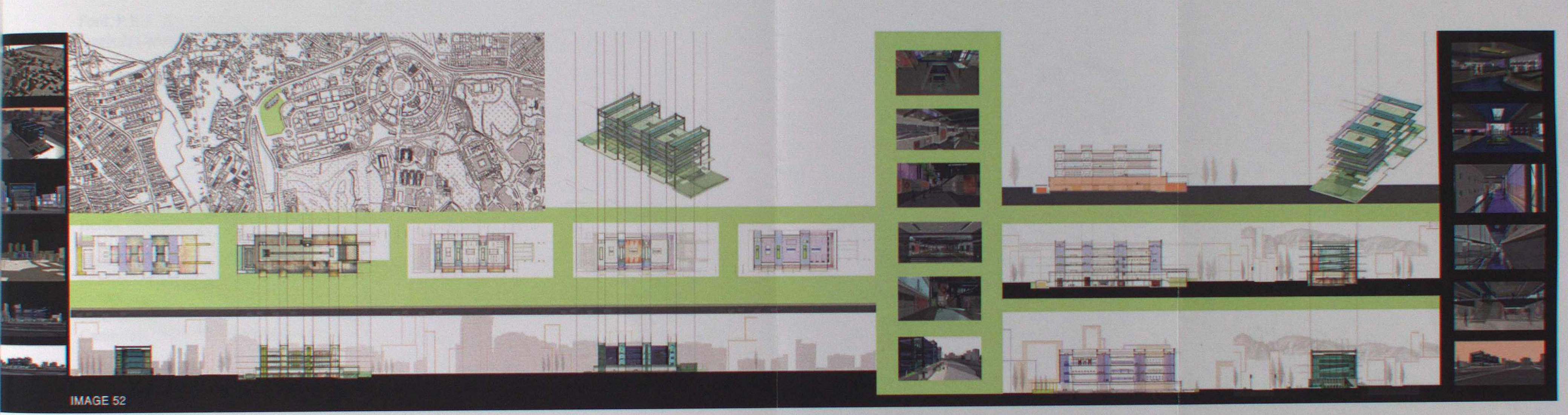




\section{Bibliography: \\ Primary Sources:}

Ardalan, Nader The Sense of Unity, Chicago, London, The University of Chicago Press 1973

Aschenbrenner, Erich Oriental Rugs, Volume 2 Persian, Munich, Oriental Textile Press, 1981

Brookes, John Gardens Of Paradise, London, Weidenfeld and Nicolson, 1978

Ford, P.R.J Oriental Carpet Design, A Guide to Traditional Motifs, Patterns and Symbols London, Thames and Hudson Ltd ,1989

Foucault, Michel OfOther Spaces, Heterotopias, Architecture/ Movement October 1984

Howard. L Parson Man East And West, Essays in East- West Philosophy Amsterdam, B.R Gruner, 1975

Jole, Iraj $\underline{\text { A research on Persian Carpets }}$ Tehran, Yasavoli, 2004

Makarem, Hassan Hearing the Past, Series of Articles, The symbol of Persian Carpet, Berlin, Gadroon 2005

Meisami, J, Scot Allegorical Gardens in Persian Poetic Tradition, International Journal of Middle East Studies. Vol 17 . No 2, 1985

McEwen, K, Indra Socrates Ancestors, An Essay on Architectural Beginnings London, Cambridge, The MIT Press, 1993

Moynihan, Elizabeth Paradise as a Garden in Persia and Mughal India London, Scolar Press, 1979

SamiAzar, Ali Gardens of Iran: Ancient Wisdom Tehran, Iranian Institute for Promotion of Visual Arts, 2004

Sooresrafil, Shirin Persian Carpets Tehran, Nashr Press, 2003

Vitruvius. Vitruvius on Architecture William Heinemann Ltd. 2 Vol, Cambridge and London, 1956

Iran Rugs, The international Monthly Magazine of Persian Rugs and Carpet, June 2002 $\mathrm{NO} 43$ 


\section{Secondary Sources:}

Burkhatr, Titus Sacred Art In East and West Perennial books, 1976

Bloom, Jonathan \& Blair, Sheila Islamic Arts, London, Phaidon Press Limited 1997

Heidegger, Martin. Building Dwelling Thinking, Basic Writings New York, Harper Collins, 1993

Heidegger, Martin. The Origin of the Work of Art, Basic Writings New York, Harper Collins, 1993

Housego, Jenny Tribal Rugs, An Introduction to the Weaving of the Tribes of Iran Ipswich, England, W S Crowell LTD, 1978

Khalili, Nader Racing Alone, A Visionary Architect's Quest for Houses Made with Earth and Fire, New York, London, Sydney, Harper \& Row, 1967

Larsen, J Elements of Weaving, Garden City, New York 1978

Rumi, Maulana Jalamuddin, Masthnawi Cambridge, University Printing House 1977

Said, Edward Said on Orientalism

The Unity of Islamic Art Kent, England, Westerham Press, 1985

Persian Carpet Appreciation Tehran, Iran Carpet Company, 1973

Architecture and Culture, Ottawa, Ontario, 1992 Carleton University 